\title{
Geographic distribution of the Cybaeus kuramotoi-group (Araneae: Cybaeidae) in Okayama, Tottori and Hyogo Prefectures, western Honshu, Japan, with descriptions of five new species.
}

\author{
Yoh Ihara ${ }^{1} \&$ Koichi Nojima ${ }^{2}$ \\ ${ }^{1}$ Hiroshima Environment \& Health Association, Hirose-kita-machi 9-1, Naka-ku, Hiroshima, 730-8631 Japan \\ E-mail: yoh.ihara@kanhokyo.or.jp \\ ${ }^{2}$ Wesco Co Ltd., Ôtedôri 2-2-13, Chuo-ku, Osaka, 540-0021 Japan \\ E-mail: k-nojima@wesco.co.jp
}

\begin{abstract}
Five new species, Cybaeus bitchuensis, C. daisen, C. mimasaka, C. momotaro, and C. tajimaensis, from eastern part of the Chugoku District consisting of Okayama, Tottori and Hyogo Prefectures, western Honshu, Japan, are described under the kuramotoi-group in the genus Cybaeus (Cybaeidae). The kuramotoi-group is medium in size and characterized by presence of the copulatory plug. Geographic distributions of the five species belonging to the kuramotoi-group and C. ashikitaensis, a species closely related to the group, are shown. Their ranges are parapatric one another except for some cases of partial overlap.
\end{abstract}

Key words - Cybaeidae, Cybaeus kuramotoi-group, Cybaeus bitchuensis n. sp., Cybaeus daisen n. sp., Cybaeus mimasaka n. sp., Cybaeus momotaro n. sp., Cybaeus tajimaensis n. sp.

One of the authors, YI, has been involved in a faunal survey and analyses of geographic differentiation of the genus Cybaeus in western Honshu and adjacent areas, Japan. The survey has revealed that each of the local species assemblages of the genus Cybaeus in western Honshu consists of several species differing one another in body size, coloration and genital morphology (Ihara 1993, 1994, 2003). Of these, the medium-sized species, which show close affinities to C. kuramotoi Yaginuma 1963 originally described from Yamaguchi Prefecture, westernmost Honshu, in external and genital morphology, are the most widespread and most diverse in western Honshu.

Close examination of distribution and geographic variation of the medium-sized group of the spiders in eastern part of the Chugoku District revealed that the group can be divided into several species whose ranges are parapatric one another and all of them remained to be undescribed except for C. ashikitaensis (Komatsu 1968). In this paper, we will present descriptions of these undescribed species, which can be recognized as members of a closely related species group, the kuramotoi-group, and C. ashikitaensis, referring to inter- and intraspecific geographic variation of the group.

\section{Materials and Methods}

\section{Morphological examinations}

All the measurements were made for the specimens immersed in $80 \%$ ethanol under a stereo dissecting microscope with an ocular micrometer. Female genitalia removed from the abdomen were cleared in hot $10 \% \mathrm{KOH}$ and $3 \% \mathrm{H}_{2} \mathrm{O}_{2}$ according to the method described in Komatsu \& Yaginuma (1968) to observe internal sclerotized structure.

The type specimens designated in this paper are deposited in the National Science Museum (Natural History), Tokyo. Other specimens are in senior author's personal collection. Data of those specimens will be given by the following order: Locality, number of individuals, date collected, and name of the collector $(\mathrm{NT}=$ Nobuo Tsurusaki, $\mathrm{KN}=$ Koichi Nojima, $\mathrm{YI}=$ Yoh Ihara).

\section{Recognition of species}

For the closely related forms among the kuramotoigroup, we adopted partial distributional overlap of the two neighboring forms without any signs of hybridization as an evidence for two distinct species which are reproductively isolated one another. On the other hand, two completely allopatric forms were considered as two independent species when morphological gap between the two are larger than the gap exhibited by the two forms with partial sympatry.

\section{The kuramotoi-group of the genus Cybaeus}

\section{Species of the kuramotoi-group in this study}

Using the two criteria for the species recognition shown above, we recognized five species in the kuramoti-group in the area studied. All the species have sufficient morphological gap when compared to C. kuramotoi that is the only described species within the group. They are: Cybaeus 


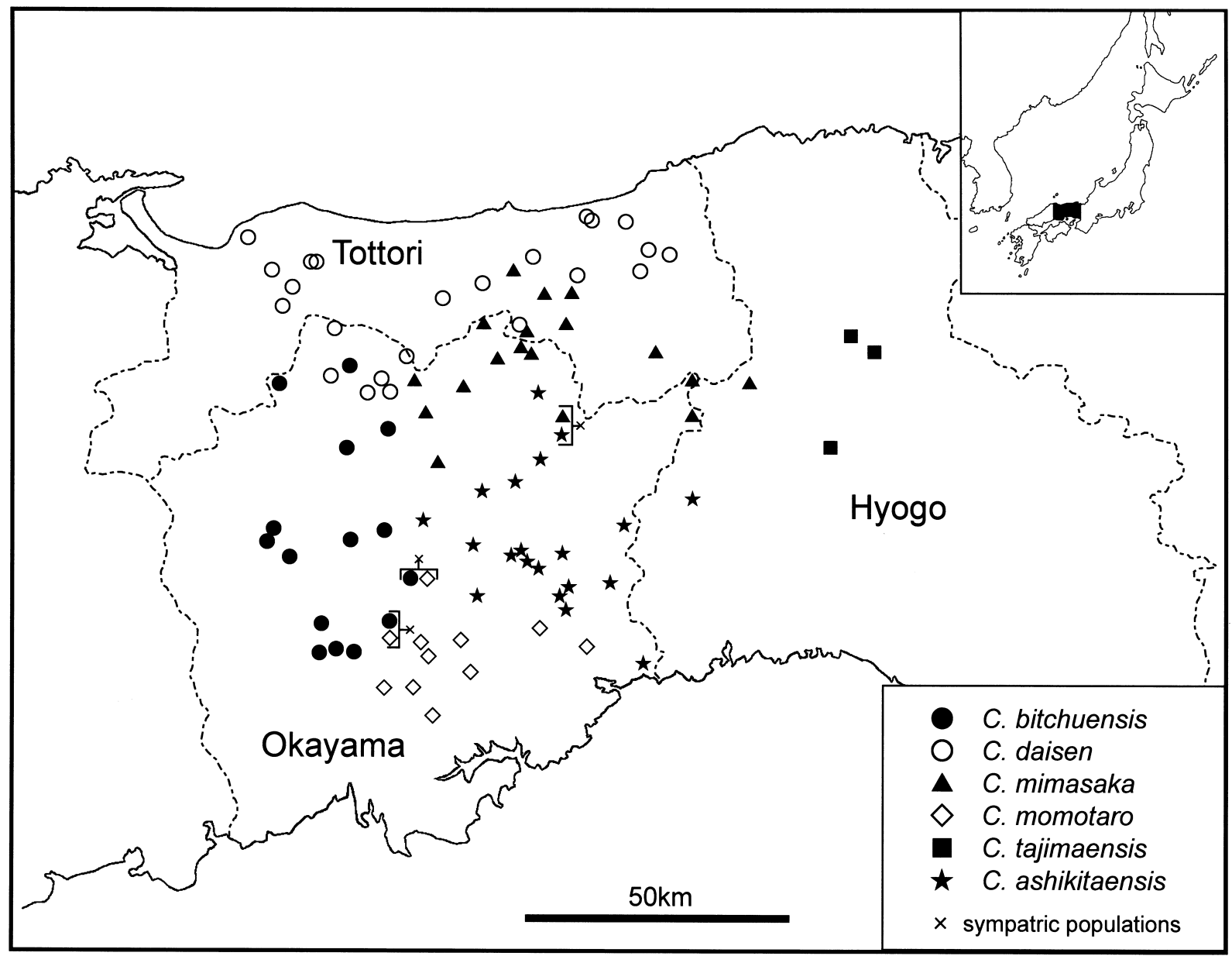

Fig. 1. Distribution of the kuramotoi-group (bitchuensis, daisen, mimasaka, momotaro and tajimaensis) of the genus Cybaeus and C. ashikitaensis in Okayama, Tottori and Hyogo Prefecture.

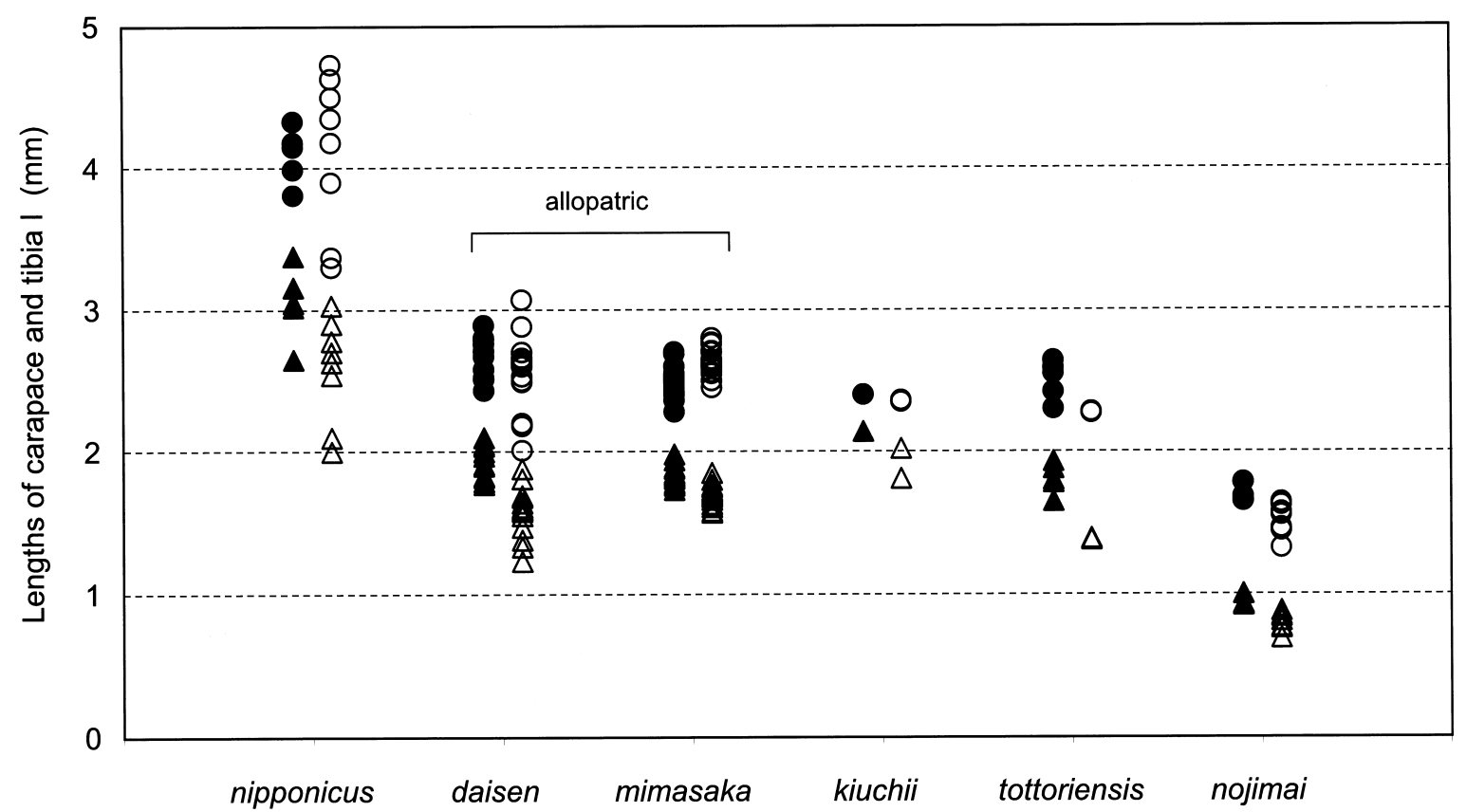

Fig. 2. Length of carapace (circles) and tibia of leg I (triangles) of six species found in eastern part of Tottori Prefecture. Note that species of the kuramotoi-group, Cybaeus daisen and C. mimasaka, are medium in size. (solid: males, open: females) 


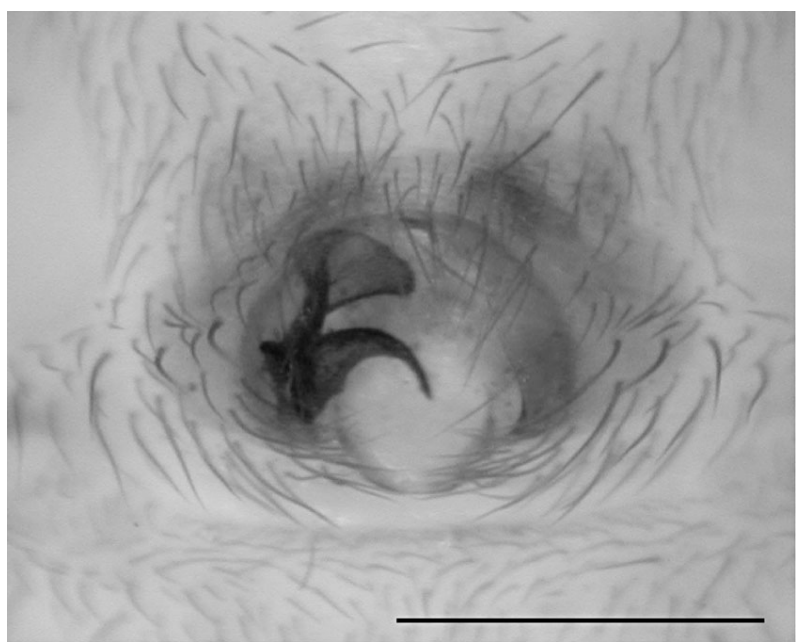

Fig. 3. An epigynum with the copulatry plug, ventral viewCybaeus mimasaka (Chizu-chô, Tottori Prefecture). (Scale: 0.5 $\mathrm{mm})$.

bitchuensis n. sp., C. daisen n. sp., C. mimasaka n. sp., C. momotaro n. sp., and C. tajimaensis n. sp.

\section{Geographic distribution}

This kuramotoi-group is distributed over western Japan, corresponding to the western Honshu, northern Shikoku and northern Kyushu (Irie \& Ono 2003; Ihara 2003, Ihara unpublished data). Each species occupies a fragment within the overall geographic range of the group.

The distributions of the species in the study area are shown in Fig. 1. It gives essentially a parapatric pattern to the distribution except for some cases of partial overlap (e. g. C. momotaro vs C. bitcyuensis; $C$. daisen vs C. mima- saka).

\section{Diagnostic characters}

Species belonging to this group are medium in size (Fig. 2) and brownish dark in color compared to other species of Cybaeus sympatrically found. This group is also characterized by having one or two copulatory plugs in inseminated female (Fig. 3). The copulatory plug is an apical element of embolus of male palp. After the copulation, it is removed from male palp and attached on crevice of epigynal plate to close copulatory pore. Female genitalia bear a large and concave opening.

\section{General feature of the group}

The general feature of the species belonging to this group is as follows (Figs. 4, 5).

Head region narrow, long and fairly large in female, but relatively small in male. Thoracic region higher than head region in male, but about as high as in female (Fig. 5). Anterior eye row slightly procurved as seen from front, posterior eye row slightly recurved (or straight as in $C$. tajimaensis) as seen from above. Ocular area about twice as wide as long. Anterior median eyes the smallest, larger than $1 / 3$ to others and smaller than $1 / 2$. Clypeus shorter than median ocular area. Chelicerae geniculate in front, female more strongly geniculate than male. Promargin of fang furrow with 3 teeth (median one the largest), retromargin with 3 or 4 teeth and several denticles, and basally with lateral condyle. Sternum longer than wide, labium wider than long. Length of legs: $4>1>2>3$. Tibia I with $2-2-2-2$ ventral spines, some prolateral and retrolateral spines; metatarsus I with $2-2-2$ ventral spines, some prolateral and retrolateral spine; tibia II with $2-2-1$ (retromargin) -2 ventral
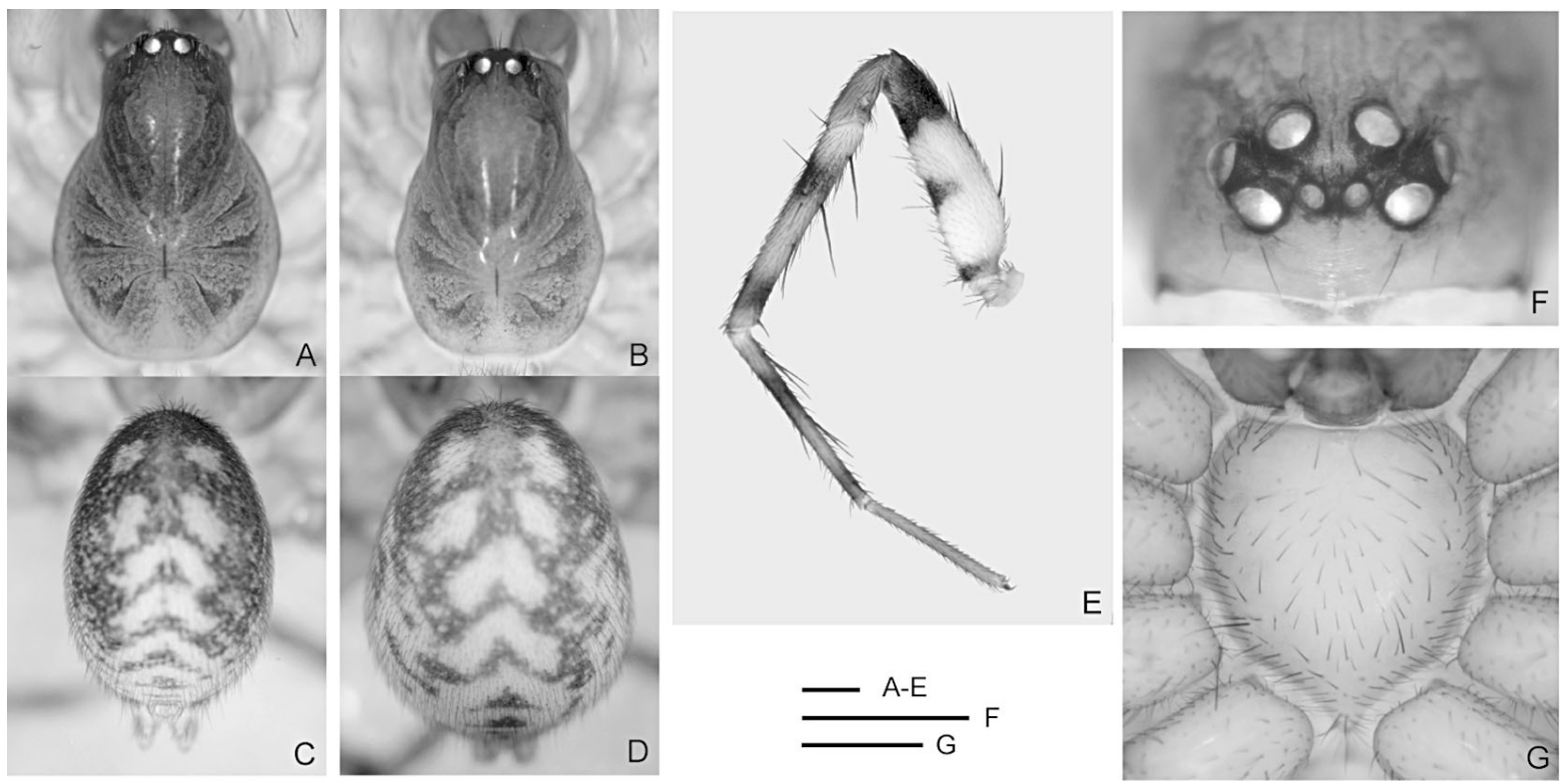

Fig. 4. Coloration pattern and diagnostic characters of Cybaeus bitchuensis (Kuse-chô, Okayama Prefecture) belonging the kuramotoigroup - A male carapace, dorsal view; B female carapace, dorsal view; C male abdomen, dorsal view; D female abdomen, dorsal view; E male left leg I, retrolateral view; F male ocular area, frontal view; G male sternum, ventral view. (Scale: 0.5 mm). 
spines, some prolateral and retrolateral spines; metatarsus II 2-2-3 ventral spines, some prolateral spines and 1 retrolateral spine.

Male palp. Relatively thick and short in proportion. Cymbium relatively short, broad in prolateral side. Tibia slightly longer than patella. Patella retrolaterally with a thumb-like apophysis furnished with conical teeth. Genital bulb circle, and relatively large. Conductor with a large apical element of embolus.

Female genitalia. Epigynum simple, with a large and concave opening; posteriorly with two copulatory pores. Spermatheca extended and bent.

Coloration (Fig. 4A-E). Carapace brown, usually with reticulate dark grayish markings on lateral sides of the head and radical bands on the thorax. Chelicerae, maxillae, labium and sternum yellowish brown to reddish brown; chelicerae darker than the others. Legs light yellow to bright yellowish brown, usually with dark annulations, occasionally with faint annulations. Dorsum of abdomen dark grayish brown with pale yellow chevron pattern.

\section{Natural history}

Spiders of the kuramotoi-group mature in autumn and overwinter as the adult stage. Since the females bearing copulatory plugs increase in number in the later season of the adult stage, it is concluded that they copulate in autumn. On the other hand, juveniles occur year round, and both adults and juveniles, which are considered to represent two different generations, can be collected at the same season. It is considered that two years are needed to mature for species of kuramotoi-group, as in Cybaeus akiensis (Ihara 2003).

Species of the group are commonly found under logs or rocks, or in the leaf litter on humid forest floor and on the soiled wall of the overhang rocks protruded on the roadside slope along the forest road. The spider is often found inside the silken tube-like retreat, which has two terminal openings (V letter-shaped types in Komatsu 1961).

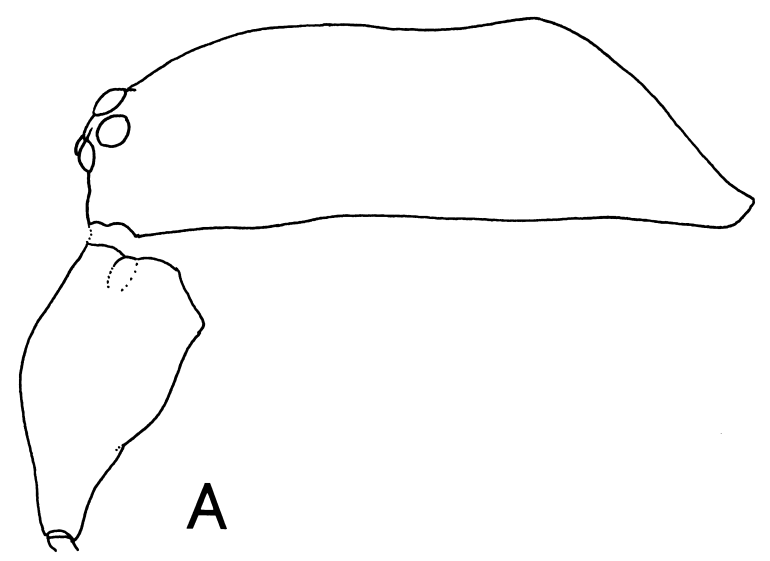

\section{Descriptions of species}

Due to the similarity in external morphology, diagnosis of each species relies primarily upon genital morphology of both sexes. In males, principal differences are in the details of patellal apophysis and apical element of conductor. In females, their epigyna closely resemble in appearance, but internal structures of genitalia are clearly distinguishable each other. They are also distinguishable by the shape of genital opening or internal structure seen through the integument. Their distributions are also effective to identification within the group.

Cybaeus bitchuensis n. sp.

[Japanese name: Bicchû-namihagumo]

(Figs. 4A-G, 5A-B, 6A-C, 7A, 8A, 9A-B)

Description. Male (holotype). Measurements (in $\mathrm{mm}$ ). Body length 4.95; carapace length 2.59 , width 1.83 , head region width 1.04; abdomen length 2.36, width 1.87; sternum length 1.24 , width 1.20 ; labium length 0.25 , width 0.36 . Length of legs (femur/ patella/ tibia/ metatarsus/ tarsus; total): Leg I: $2.01 / 0.78 / 1.74 / 1.79 / 1.25 ; 7.57$. Leg II: $1.96 /$ $0.78 / 1.66 / 1.69 / 1.16 ; 7.25$. Leg III: $1.80 / 0.74 / 1.33 / 1.67 /$ $1.00 ; 6.54$. Leg IV: $2.26 / 0.77 / 1.90 / 2.25 / 1.19 ; 8.37$ Ocular area: length 0.34 , width 0.64 .

Palp (Figs. 6A-C, 7A, 8A). Patellal apophysis relatively small, with 10 conical teeth. Conductor with small forked apical element of embolus.

Female (one of paratypes). Measurements (in mm). Body length 5.15; carapace length 2.43, width 1.66 , head region width 1.10; abdomen length 2.76 , width 2.24; sternum length 1.19 , width 1.13 ; labium length 0.27 , width 0.40 . Length of legs (femur/ patella/ tibia/ metatarsus/ tarsus; total): Leg I: $1.74 / 0.75 / 1.50 / 1.39 / 0.92 ; 6.30$. Leg II: $1.70 /$ $0.71 / 1.35 / 1.32 / 0.82$; 5.90. Leg III: $1.46 / 0.67 / 1.06 / 1.25 /$ 0.74; 5.18. Leg IV: $1.90 / 0.68 / 1.57 / 1.85 / 0.96 ; 6.96$. Ocular area: length 0.34 , width 0.68 .

Genitalia (Fig. 9A-B). Opening of epigynum trapezoid

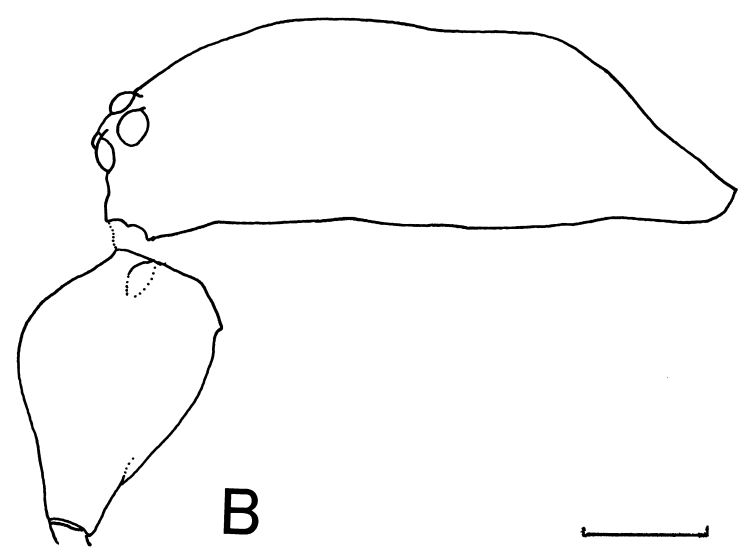

Fig. 5. Shape of carapace and chelicerae of Cybaeus bitchuensis (Kuse-chô, Okayama Prefecture), lateral view- A male; B female. (Scale: $0.5 \mathrm{~mm}$ ). 


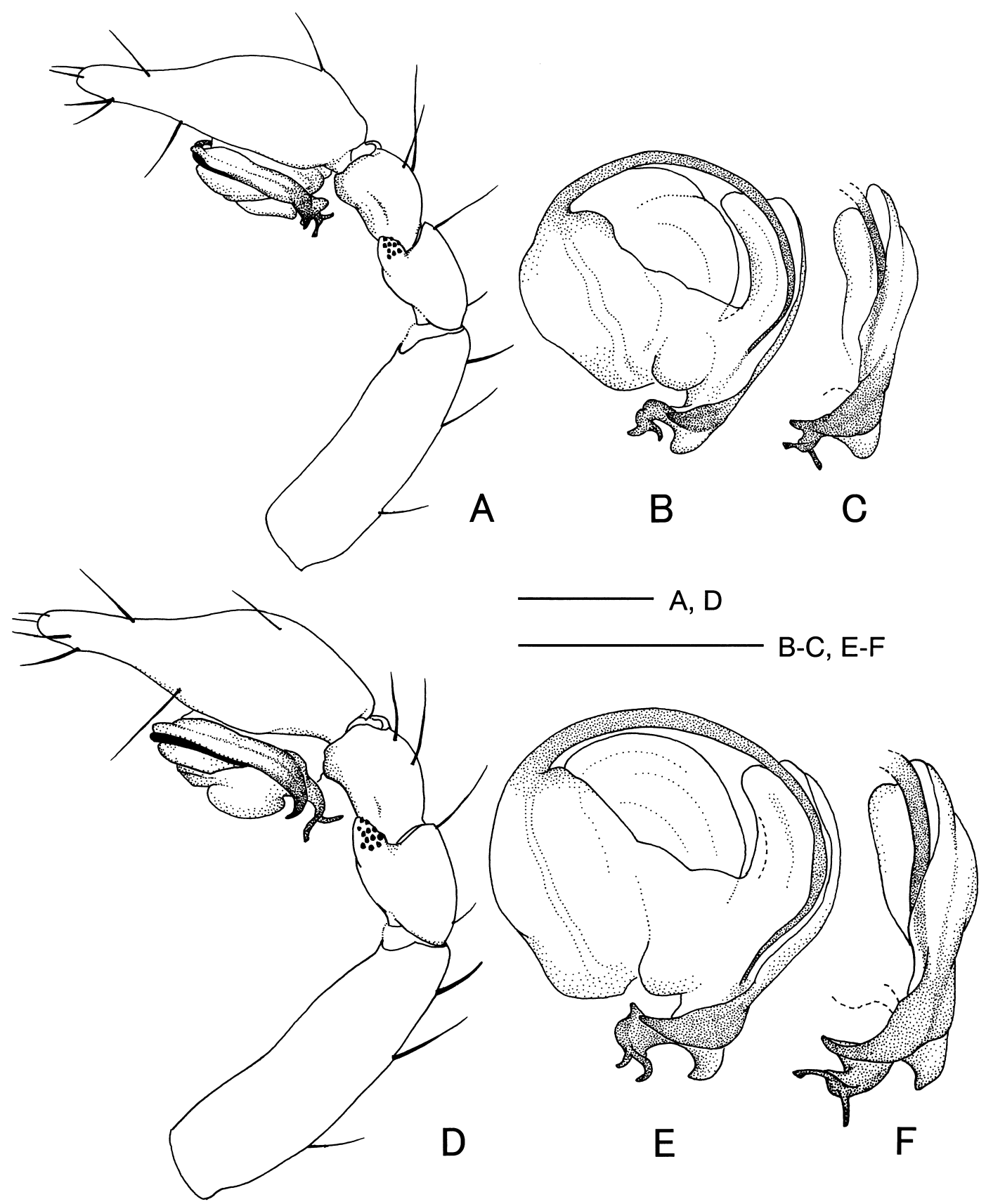

Fig. 6. Male left palp of Cybaeus bitchuensis (holotype) and C. daisen (holotype): A-C C. bitchuensis; D-F C. daisen- A, D lateral view; $\mathrm{B}$, E genital bulb, ventral view; C, F apical element of embolus, ventrolateral view. (Scale: $0.5 \mathrm{~mm}$ )

with round angles.

Type series. Idono, Kamimizuta, Hokubô-chô, Jôbô-gun,

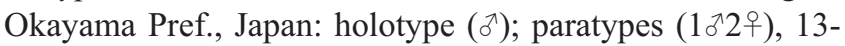
X-1990, Y. Ihara leg.

Other specimens examined. OKAYAMA PREF. Takahashishi: Mt. Gagyû-zan, 1우, 11-II-1989, YI; Ôkubo, 1ㄲㅇㅜ, 23-XII1989, KN; Matsuyama, Narai, 8$\overbrace{}^{3} 13$ 우, 17-X-1990, KN. Niimi-

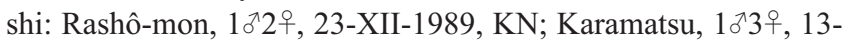
X-1990, YI; Osakabe-gawa Dam, 2ㅇ, 24-V-1991, YI. Kaga-gun, Kibichûô-chô: Hiromo, 1ㅇ, 6-II-1989, KN, 1ðㄱ, 18-X-1989, KN, 1우, 19-X-1989, KN; Takatomi, 4o7우, 16-X-1990, KN; Kayô- chô, 1우, 20-V-1989, KN. Maniwa-gun, Katsuyama-chô, Kanbano-taki Falls, 3ð’2우, 24-IX-1989, YI. Ochiai-chô, Taharasanjô, 5ð', 3-XI-1990, KN. Shinjô-son, Mt. Kenashi: 1ㅇ, 24-IX-1989, YI, 1우, 20-V-1990, KN, 238 우, 21-X-1990, KN. Kawakami-son, Norito, 4`3우, 8-X-1994, YI. Kuse-chô, Kashinishi, Ashio-daki Falls: 42우, 11-X-2004, YI; 1ð1우, 11-X-2004, Kai Ihara.

Variation. Internal structure of female genitalia varies among populations (Fig. 10).

Distribution. Northwestern part of Okayama Prefecture, western Honshu, Japan (Fig. 1). This species is distributed over the area roughly encompassed by the Takahashi River 
and the Asahi River.

Remarks. Male palp and epyginum of Cybaeus bitchuensis resemble those of $C$. daisen very much. However, copulatory organs of this species are distinctly smaller than those of $C$. daisen. They can be distinguished also in patellal apophysis and apical element of embolus of male palp and internal structure of female genitalia.

Cybaeus daisen n. $\mathrm{sp}$.

[Japanese name: Daisen-namihagumo]

(Figs. 6D-F, 7B, 8B, 11A, 12A-D)

Description. Male (holotype). Measurements (in mm). Body length 5.75; carapace length 2.98, width 2.10, head region width 1.20; abdomen length 2.75 , width 2.18 ; sternum length 1.33 , width 1.30 ; labium length 0.29 , width 0.43 . Length of legs (femur/ patella/ tibia/ metatarsus/ tarsus; total): Leg I: $2.30 / 0.87 / 2.14 / 2.12 / 1.51 ; 8.94$. Leg II: $2.29 /$ 0.88/ 1.94/2.04/ 1.36; 8.51. Leg III: 2.06/ 0.82/ 1.56/1.95/ 1.16 ; 7.55. Leg IV: $2.56 / 0.84 / 2.18 / 2.70 / 1.41 ; 9.69$. Ocular area: length 0.36 , width 0.76 .

Palp (Figs. 6D-F, 7B, 8B, 11A). Cymbium broad in prolateral side. Patellal apophysis relatively large, with 12 conical teeth. Conductor with forked apical element of embolus.

Female (one of paratypes). Measurements (in mm).
Body length; 6.00; carapace length 2.73, width 1.87 , head region width 1.20; abdomen length 3.27 , width 2.50 ; sternum length 1.29 , width 1.20 ; labium length 0.30 , width 0.39 . Length of legs (femur / patella / tibia / metatarsus / tarsus; total): Leg I: $2.00 / 0.81 / 1.77 / 1.62 / 1.02 ; 7.22$. Leg II: $1.82 / 0.80 / 1.59 / 1.58 / 1.00 ; 6.79$. Leg III: $1.64 / 0.76 /$ 1.20/ 1.58/ 0.83; 6.01. Leg IV: 2.18/ 0.78/ 1.80/ 2.17/ 1.05; 7.98. Ocular area: length 0.38 , width 0.76 .

Genitalia (Fig. 12A-D). Opening of epigynum anteriorly rounded and posterioly spread.

Type series. Mt. Daisen, Daisen-chô, Saihaku-gun, Tottori Pref., Japan: holotype ( $\overbrace{}^{\prime})$; paratypes (1 $\overbrace{}^{\circledR} 2$ 우), 16-IX1990, Y. Ihara leg.

Other specimens examined. OKAYAMA PREF. Maniwagun, Yubara-chô: Shirane Valley, 4o11우, 15-IX-1990, YI; Awadani, 5 $\delta^{\top} 9$ 우, 8-X-1994, YI; Hijiya, right bank of Yubara Lake, 2ㅈ1우, 11-X-2004, YI, 2ð3우, 11-X-2004, K. Ihara; Yashiro, $2 \Im^{\top} 1$ 우, 11-X-2004, YI. Kawakami-son, Kami-Hiruzen, 2ð’, 24-IX-1989, YI. Chûka-son: Tsuguro Highlands, 2우, 9-X1990, KN; north entrance of the Kumai-tôge Tunnel, $1{ }^{2} 2$ 운, 26X-1993, NT. TOTTORI PREF. Tottori-shi: Iwatsubo, $10^{\circledR} 1$ 우, $23-$ X-1991, YI; Koyama, Urayama, 1ð, 30-XI-1991, NT; Koyama, Tariyama, 1 $\varsigma^{` 1} 1$ ㅇ, 30-XI-1991, NT; Koyama, Campus of Tottori University, 1§ð, 12-X-1989, NT; Koyama, Tenjinyama, 1우 16XII-1991, NT; Ôchidani, 1우, 22-XI-1991, NT. Kurayoshi-shi, Kamogôchi, 1ð33우, 16-X-1991, KN; Kokufu-chô, Tamaboko, 2

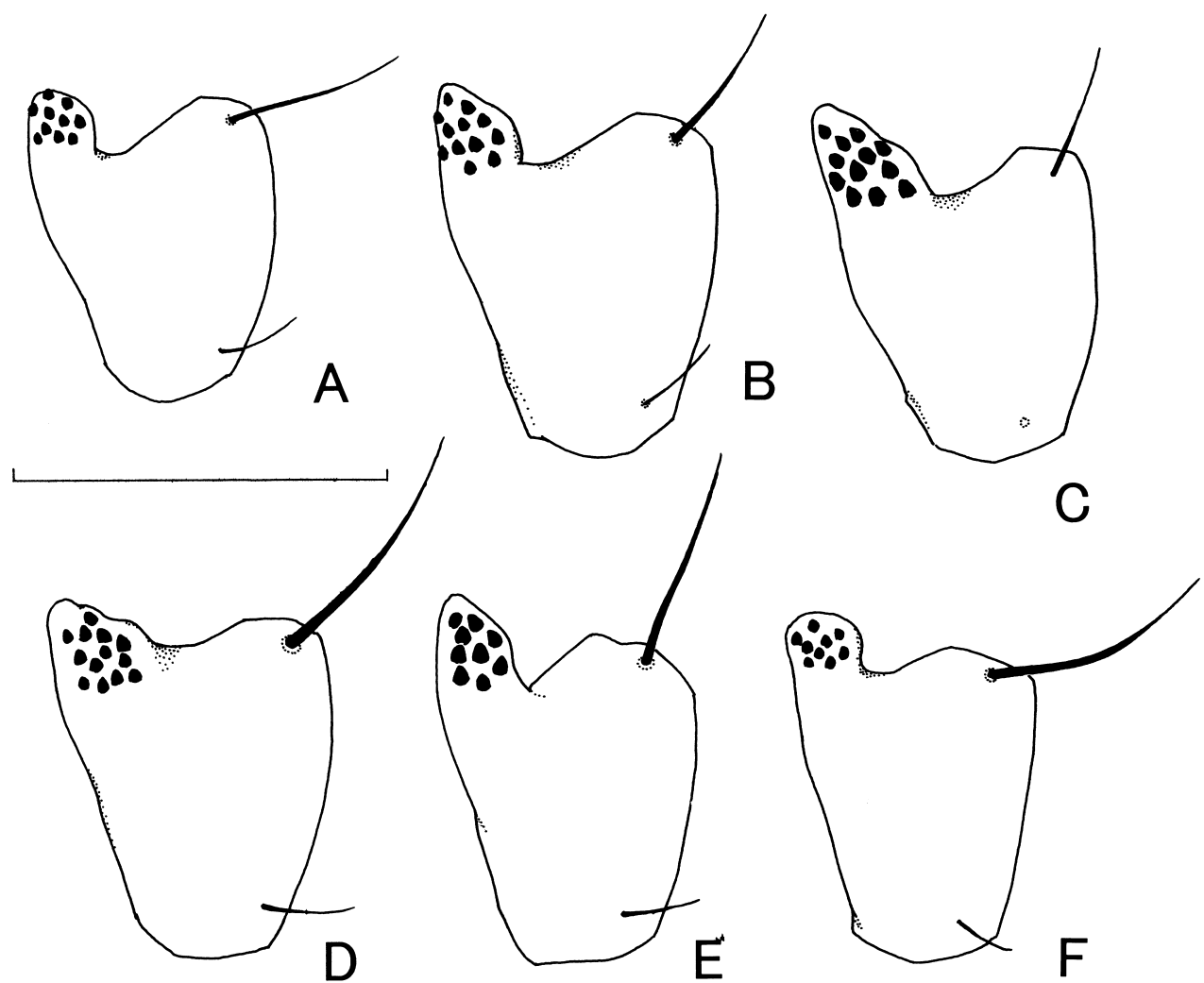

Fig. 7. Patella of male palp (left) of the Cybaeus kuramotoi-group and C. ashikitaensis, dorsolateral view- A C. bitchuensis (holotype); B C. daisen (holotype); C C. mimasaka (holotype); D C. momotaro (holotype); E C. tajimaensis (holotype); F C. ashikitaensis (Saeki-chô, Okayama Prefecture). (Scale: $0.5 \mathrm{~mm}$ ) 
๙1우, 6-X-1993, KN; Tono, 2ㅈ1우, 22-X-1991, YI; Saji-chô, Naka, 1우, 18-IX-1991, YI; Shikano-chô, Obata, 3우, 20-XI-1989, NT. Yazu-gun, Kôge-chô, Hanabara, 2ð2우, 23-X-1991, YI. Tôhaku-gun, Misasa-chô, Mt. Mitoku-san, Sanbutsu-ji Temple, 5 ‘9우, 15-IX-1990, YI. Kotoura-chô, Mt. Senjô-zan, 2ð6우, 16-IX1990, YI. Saihaku-gun, Daisen-chô: Mt. Daisen, 5ð5우, 16-IX1990, YI; Toyofusa, 1우, 21-IX-1992, KN; Mt. Daisen, San-nosawa, 6구우, 9-X-1994, YI, 2주우, 9-X-1994, KN; Nagata, 1우, 24-III-1995, KN. Nakayama-chô, Mt. Senjô-zan, 2ð33우, 16-IX1990, YI.

Variation. Internal structure of female genitalia consid- erably varies among populations (Fig 12). Female genitalia of eastern populations are more slender than those of western populations including type locality.

Distribution. Tottori Prefecture and northwestern part of Okayama Prefecture, western Honshu, Japan (Fig. 1).

Remarks. Male palp of Cybaeus daisen also resembles that of $C$. mimasaka. However, details of tibia, patellal apophysis and apical element of embolus of male palp of this species can be distinguished from those of C. mimasaka. Female genitalia of these species are distinct each other.
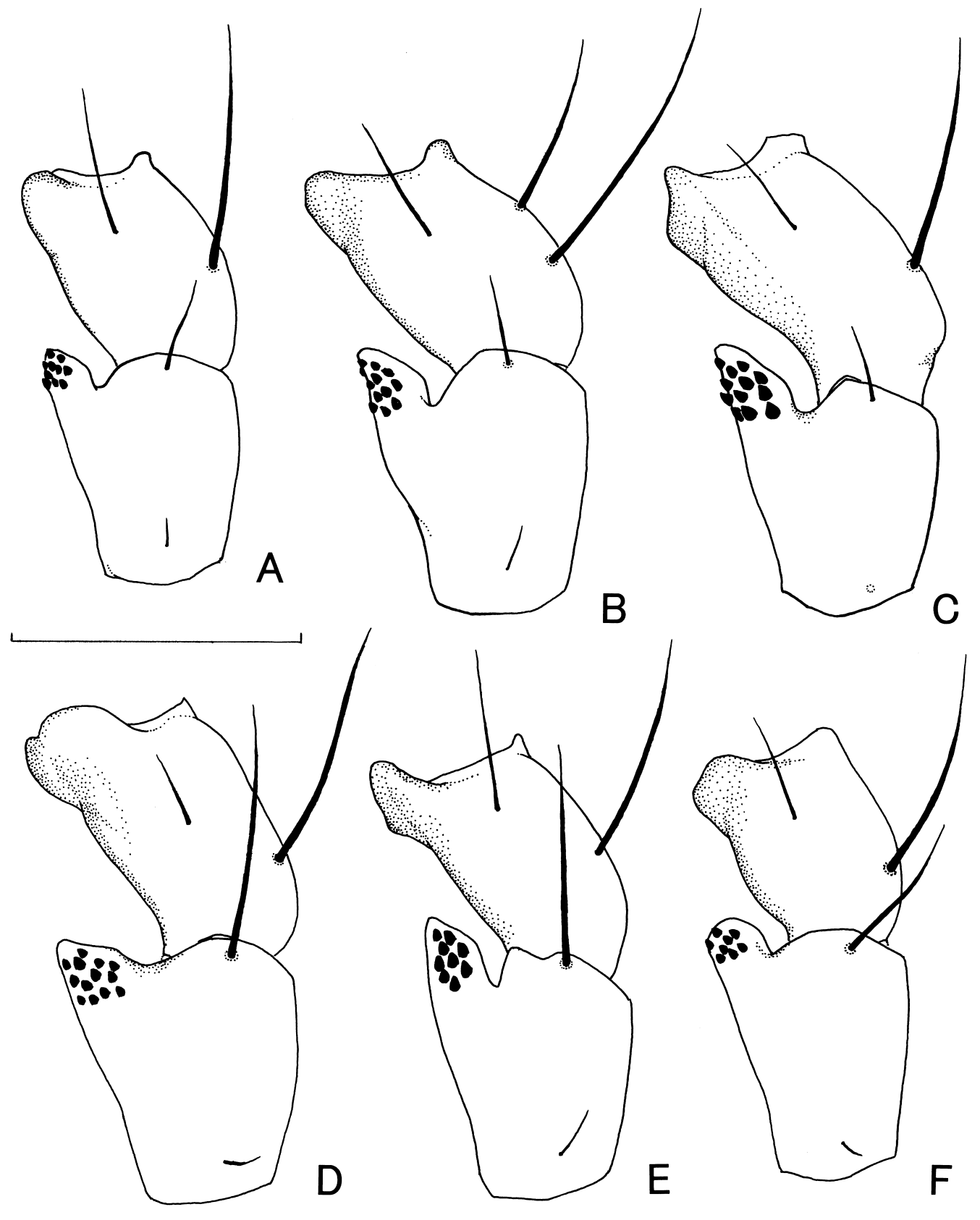

Fig. 8. Tibia and patella of male palp (left) of the Cybaeus kuramotoi-group and C. ashikitaensis, dorsal view- A C. bitchuensis (holotype); B C. daisen (holotype); C C. mimasaka (holotype); D C. momotaro (holotype); E C. tajimaensis (holotype); F C. ashikitaensis (Saeki-chô, Okayama Prefecture). (Scale: $0.5 \mathrm{~mm}$ ) 


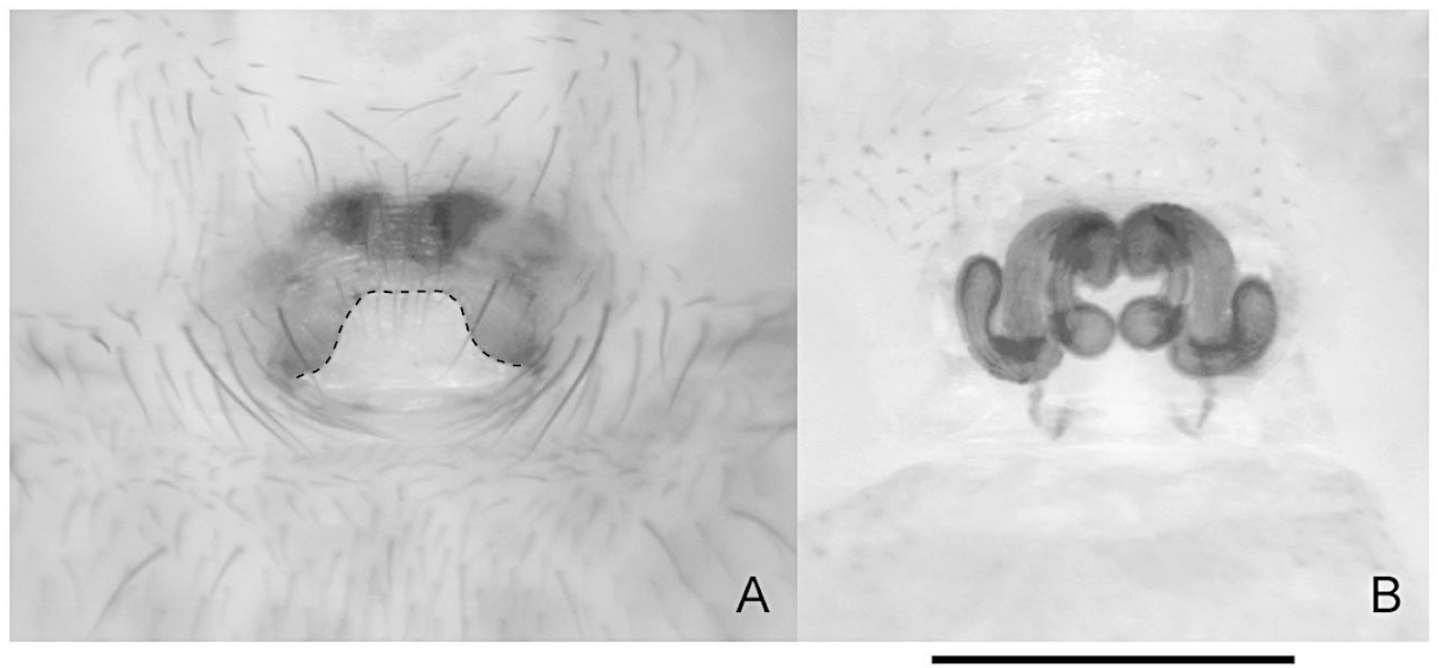

Fig. 9. Female genitalia of Cybaeus bitchuensis (paratype) - A epigynum, ventral view; B internal structure, dorsal view. (Dashed line: edge of epigynal plate, Scale: $0.5 \mathrm{~mm}$ )

Cybaeus mimasaka n. sp.

[Japanese name: Mimasaka-namihagumo]

(Figs. 7C, 8C, 11B, 13A-C, 14A-B)

Description. Male (holotype). Measurements (in mm). Body length 4.60; carapace length 2.58 , width 1.87 , head region width 1.06; abdomen length 2.16, width 1.60; sternum length 1.18 , width 1.14 ; labium length 0.25 , width 0.42 . Length of legs (femur/ patella/ tibia/ metatarsus/ tarsus; total): Leg I: $2.11 / 0.78 / 1.86 / 1.84 / 1.28 ; 7.87$. Leg II: 2.03/ $0.78 / 1.65 / 1.71 / 1.18$; 7.35 . Leg III: $1.82 / 0.69 / 1.31 / 1.65 /$ 0.98 ; 6.45. Leg IV: $2.18 / 0.72 / 1.85 / 2.34 / 1.27 ; 8.36$. Ocular area: length 0.33 , width 0.67 .

Palp (Figs. 7C, 8C, 11B, 13A-C). Tibia strongly bent. Patellal apophysis relatively large, with 12 conical teeth. Conductor with a large and branched apical element of embolus.

Female (one of paratypes). Measurements (in mm). Body length; 5.45; carapace length 2.55, width 1.71 , head region width 1.14; abdomen length 2.90 , width 2.34 ; sternum length 1.19 , width 1.11 ; labium length 0.26 , width 0.42. Length of legs (femur/ patella/ tibia/ metatarsus/ tarsus; total): Leg I: $1.92 / 0.77 / 1.74 / 1.60 / 0.98 ; 7.01$. Leg II: 1.81/ 0.76/ 1.53/ 1.55/ 0.94; 6.59. Leg III: $1.62 / 0.70 / 1.53 /$ 1.55/ 0.94; 5.83. Leg IV: $2.02 / 0.73 / 1.77 / 2.13 / 1.05 ; 7.70$. Ocular area: length 0.35 , width 0.69 .

Genitalia (Fig. 14A-B). Opening of epigynum large and longer than wide. End of spermatheca strongly extended and bent.

Type series. Ashizu Valley, Chizu-chô, Yazu-gun, Tottori Pref., Japan: holotype ( $\left.\delta^{\top}\right)$; paratypes (2ㅇ), 14-X1990, Y. Ihara leg.

Other specimens examined. OKAYAMA PREF. Maniwagun, Chûka-son, Mt. Yamanori-yama, 2ð22우, 29-X-1990, KN. Tomata-gun, Kamo-chô: Mt. Sanjûningasen, 10^, 19-XI-1989,
YI; Kurami, 1ð2우, 1-IX-1990, KN, 1ð, 27-IX-1990, KN, 1ð2ㅇ, 5-XII-1990, KN. Tomi-son, Shiraka-keikoku Valley, 3 35 우, 19XI-1989, YI \& KN. Okutsu-chô, Okutsu-kei Gorge, 4خ'우, 19XI-1989, KN. Kamisaibara-son: Endô, 1ㅇ, 10-VI-1990, KN; Iwai-daki Falls, 6 $3^{7} 1$ 우, 14-X-1990, YI, $13^{1} 5$ 우, 14-X1990, KN. Katsuta-gun, Nagi-chô, Mt. Takiyama: 3ㅇ, 19-III-1989, KN; 2ㅈ1우, 22-X-1989, KN. Aida-gun, Higashi-awakura-son, Mt. Ushiroyama: 106우, 4-XII-1989, KN; 1ㅇ, 14-XI-1992, KN. Nishi-awakura-son: Wakasugi Pass, 3ㅇ, 12-XI-1989, KN; Wakasugi, 1우, 2-VI-1990, KN, 1ㅇ, 14-XI-1992, KN. Kume-gun, Kume-chô, Miyabekami, 4ð 4우, 3-XI-1990, KN. TOTTORI PREF. Tottori-shi: Kawahara-chô: Kitamura, 1ㅈ1우, 14-X-1990, KN, 3누우, 14-X-1990, YI; Kitamura, Gongen Shrine, 1 $\delta^{7} 2$ 우, 22X-1991, YI; Mitaki-kei Gorge, 3ð 5 ㅇ, 22-X-1991, YI; Saji-chô, Kasegi, Sasao Shrine, 1우, 14-X-1990, YI, 1즈, 14-X-1990, KN;

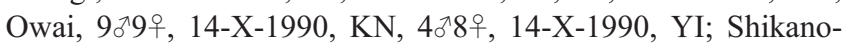
chô, KôchI, 1+9, 6-I-1994, NT. Yazu-gun, Chizu-chô, Ashizu Valley, 3ช̛4우, 14-X-1990, KN. Tôhaku-gun, Misasa-chô, Oshika-keikoku Valley, 2우, 16-IX-1990, YI. HYOGO PREF. Shisô-gun, Haga-chô, Akasai-keikoku Valley, $1{ }^{\circledR} 1$ 우, 30-XII1989, KN.

Variation. Internal structure of female genitalia considerably varies among populations (Fig. 15).

Distribution. Northern part of Okayama Prefecture, southeastern part of Tottori Prefecture and northeastern part of Hyogo Prefecture, western Honshu, Japan (Fig. 1).

Remarks. Epigynum of this species resembles that of Cybaeus kuramotoi. However, internal structure of female genitalia of these species are distinct each other (compare Fig. 14 and figure 15 in Ihara 2003). Spermatheca of this species is larger, and more acutely bent than that of $C$. kuramotoi. Furthermore, their distributions are separated into two different areas. C. kuramotoi is distributed in Yamaguchi, Hiroshima and Shimane Prefectures, westernmost Honshu and northern Kyushu (Irie \& Ono 2003; Ihara 2003). 


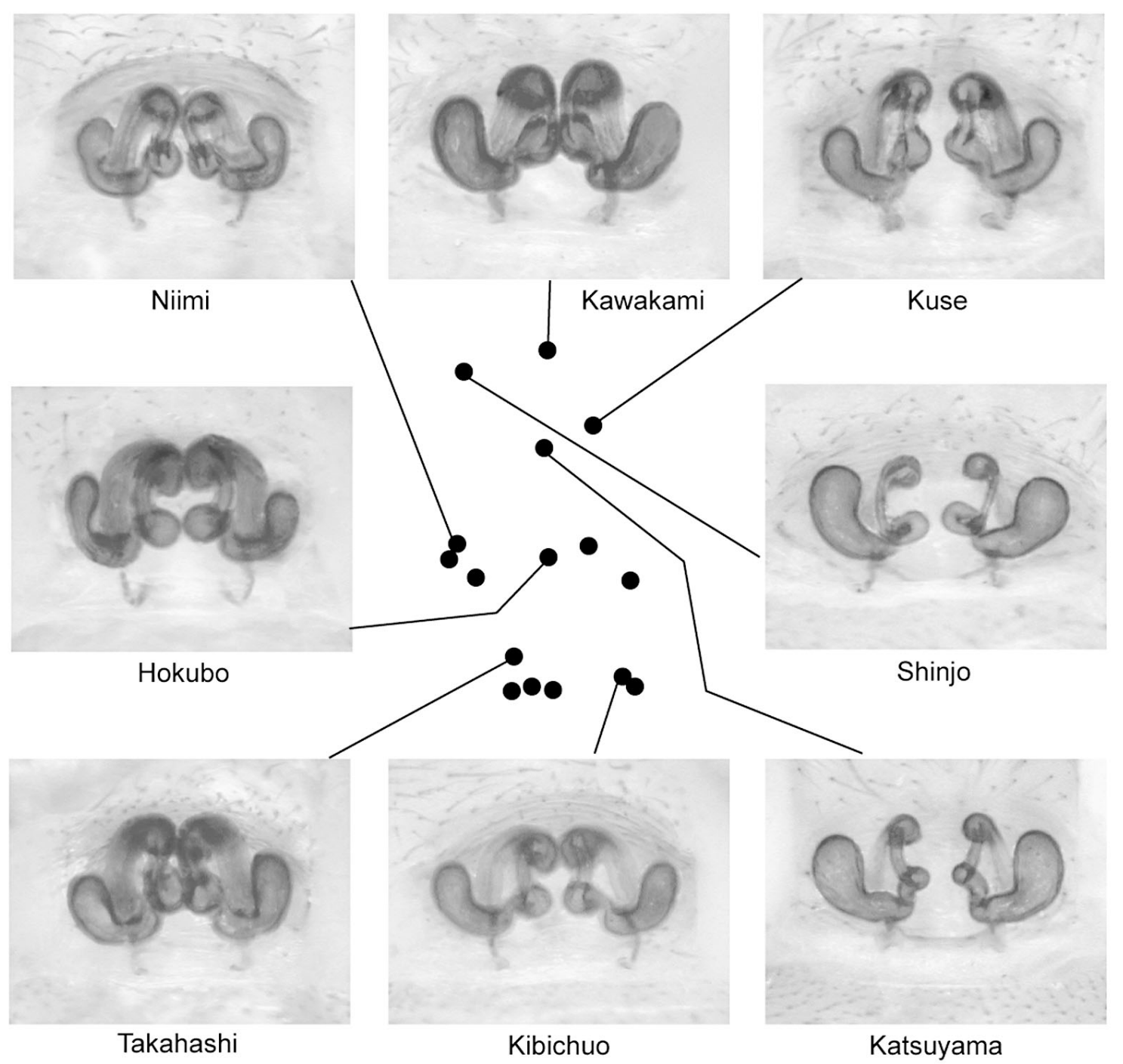

Fig. 10. Geographic variation of female genitalia of Cybaeus bitchuensis.

Cybaeus momotaro n. sp.

[Japanese name: Bizen-namihagumo]

(Figs. 7D, 8D, 16A-C, 17A-B)

Description. Male (holotype). Measurements (in mm). Body length 5.35; carapace length 2.78, width 1.92, head region width 1.15 ; abdomen length 2.55 , width 2.04 ; sternum length 1.30 , width 1.18 ; labium length 0.30 , width 0.41 . Length of legs (femur/ patella/ tibia/ metatarsus/ tarsus; total): Leg I: $2.12 / 0.86 / 2.00 / 1.93 / 1.28 ; 8.19$. Leg II: $1.96 /$ 0.82/ 1.74/ 1.73/ 1.16; 7.41. Leg III: $1.82 / 0.79 / 1.37 / 1.70 /$ 0.97 ; 6.65. Leg IV: $2.18 / 0.81 / 1.96 / 2.43 / 1.23 ; 8.61$. Ocular area: length 0.32 , width 0.72 .

Palp (Figs. 7D, 8D, 16A-C). Patellal apophysis relatively wide, with 13 conical teeth. Conductor with long apical element of embolus.

Female (one of paratypes). Measurements (in mm). Body length; 6.15; carapace length 2.88, width 1.90, head region width 1.28; abdomen length 3.42 , width 2.35 ; sternum length 1.34 , width 1.19 ; labium length 0.30 , width 0.41 . Length of legs (femur/ patella/ tibia/ metatarsus/ tarsus; total): Leg I: $1.97 / 0.84 / 1.71 / 1.56 / 0.99 ; 7.07$. Leg II: 1.84/ 0.82/ 1.50/ 1.48/ 0.82; 6.46. Leg III: $1.66 / 0.75 / 1.20 /$ $1.43 / 0.81 ; 5.85$. Leg IV: $2.04 / 0.77 / 1.72 / 2.04 / 1.00 ; 7.57$. Ocular area: length 0.38 , width 0.78 .

Genitalia (Fig. 17A-B). Opening of epigynum large and semicircle.

Type series. Kuro-o, Sôja-shi, Okayama Pref., Japan: holotype ( $\left.\jmath^{\top}\right)$; paratypes (1 ${ }^{2} 2$ 우), 12-XI-1995, K. Nojima leg.

Other specimens examined. OKAYAMA PREF. Okayamashi: Kanayamaji, 10, 12-II-1989, YI; Kibitsu-jinja Shrine, 1우, 12-I-1992, KN; Kamitsuchida, 5ㅇ, 2-II-1996, KN; Ishizuma, 1 우 2-II-1996, KN; Mt. Honjin-yama, 13̋4우, 11-II-1996, KN. Sôjashi, Kuro-o, 1주우, 12-XI-1995, KN. Bizen-shi, 2우, 1-II-1989, YI. Mitsu-gun, Mitsu-chô: Kanagawa, 2子'2우, 15-I-1990, KN; Mt. Honjin-yama, 1 $\delta^{2}+$, 19-III-1990, KN. Kaga-gun, Kamo-

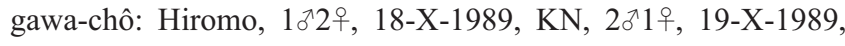




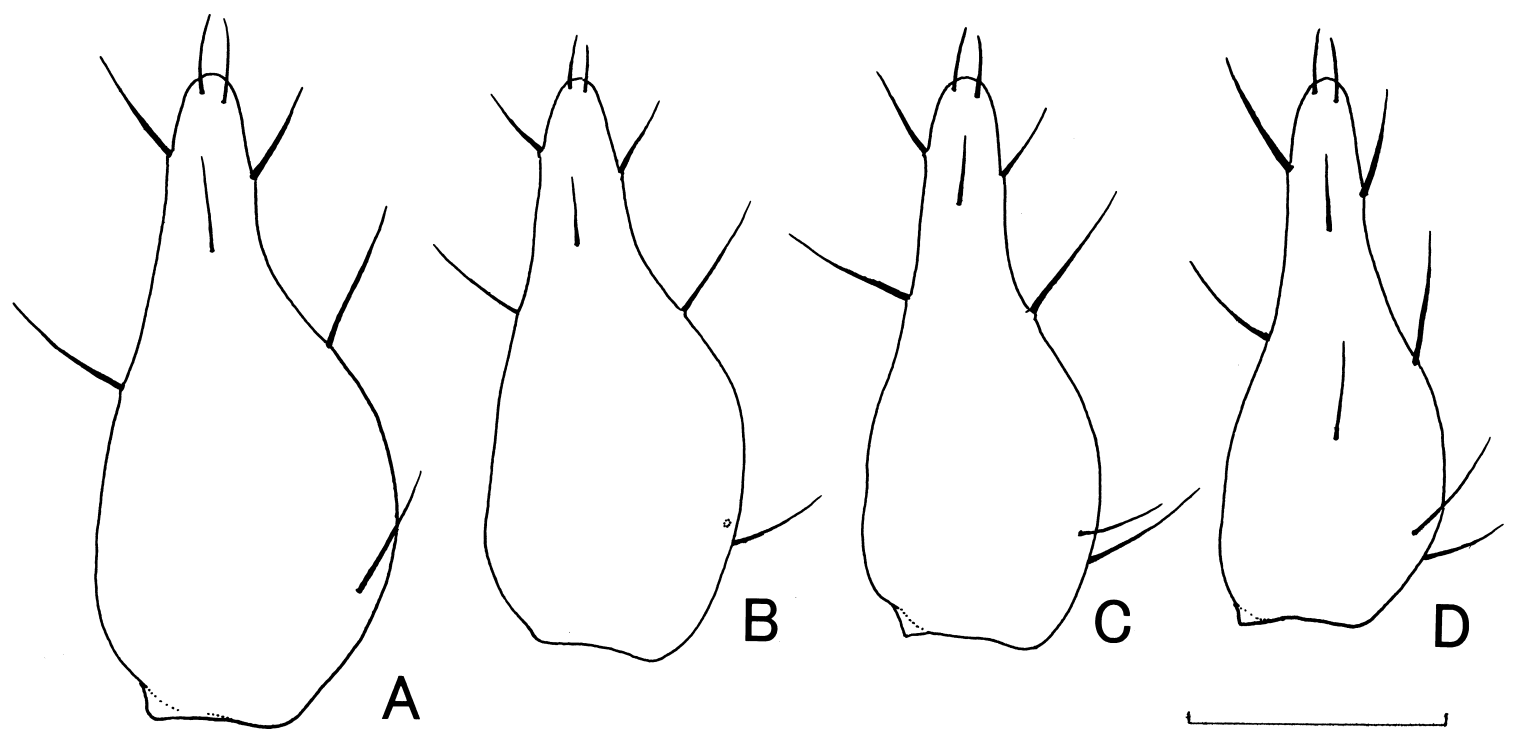

Fig. 11. Cymbium of male left palp, dorsal view - A Cybaeus daisen (holotype); B C. mimasaka (holotype); C C. tajimaensis (holotype); D C. ashikitaensis (Saeki-chô, Okayama Prefecture). (Scale: $0.5 \mathrm{~mm}$ )
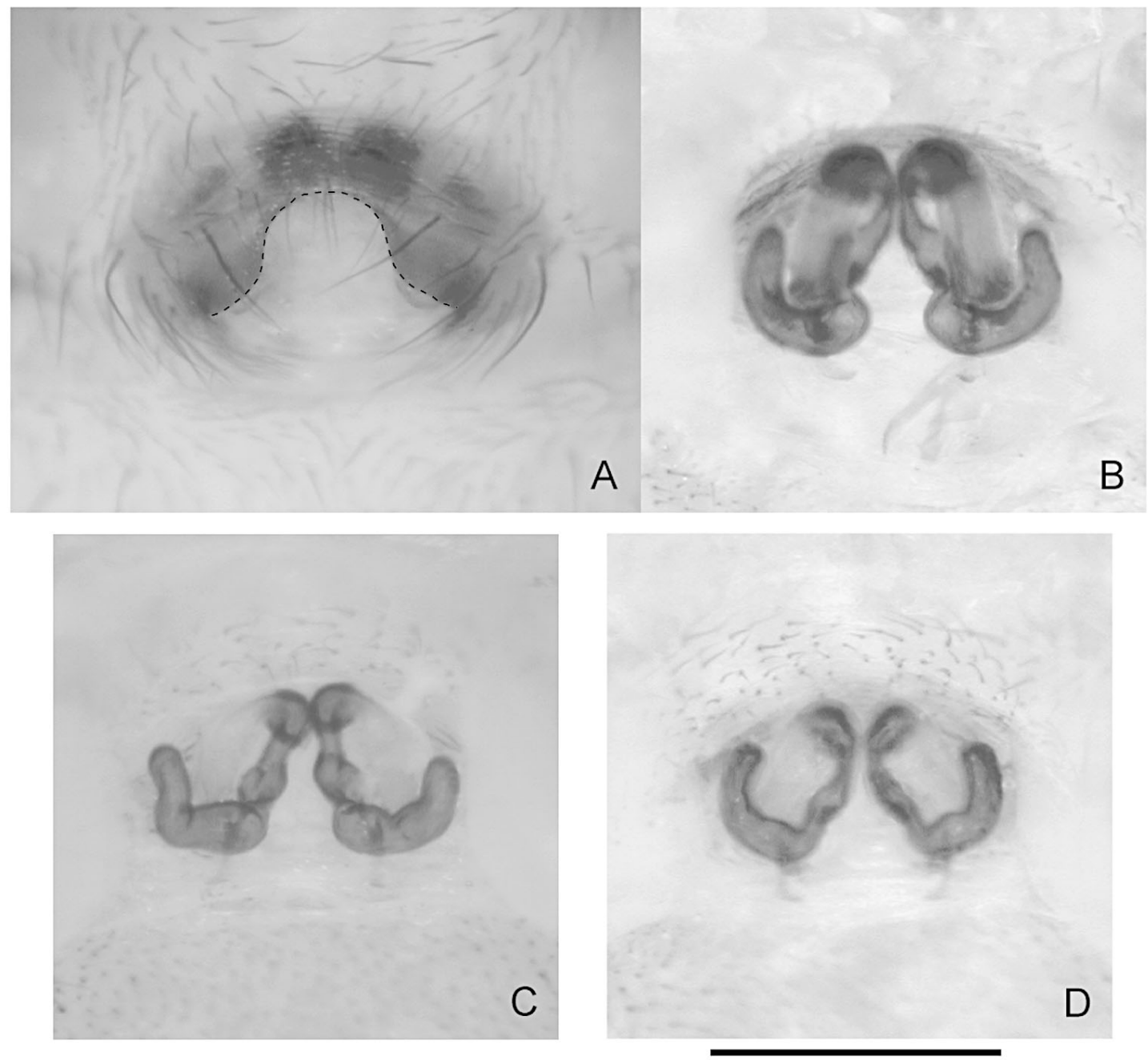

Fig. 12. Female genitalia of Cybaeus daisen: A-B paratype from Mt. Daisen, western area of its distributional range; C Misasa-chô, central area of its distributional range; Kokufu-chô, Tottori-shi, eastern area of its distributional range- A epigynum, ventral view; B-D internal structure, dorsal view. (Dashed line: edge of epigynal plate, Scale: $0.5 \mathrm{~mm}$ ) 

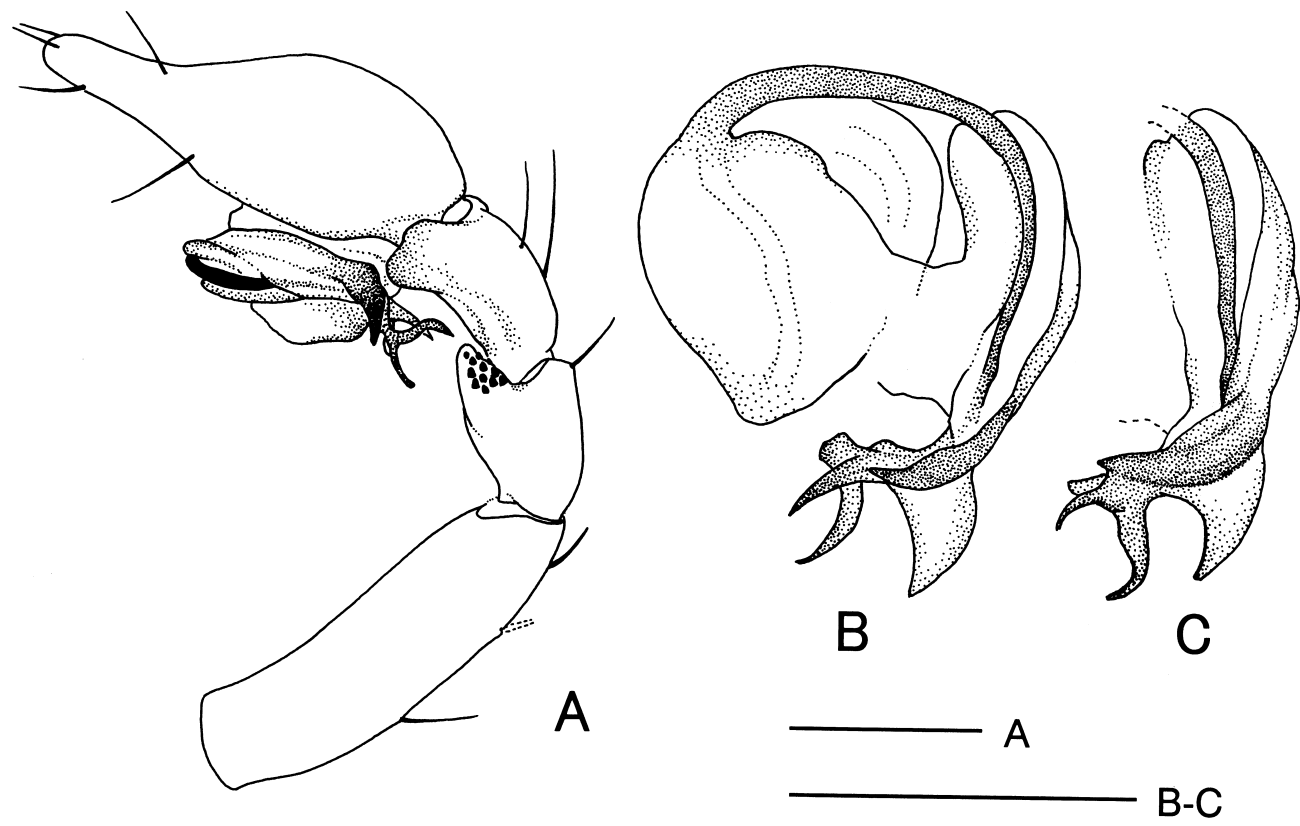

Fig. 13. Male left palp of Cybaeus mimasaka (holotype) - A lateral view; B genital bulb, ventral view; C apical element of embolus, ventrolateral view. (Scale: $0.5 \mathrm{~mm}$ )

KN; Takatomi, 1ठ, 15-I-1990, KN. Akaiwa-gun, Kumayamachô, Okuyoshihara, 1ð4우, 10-X-1990, KN.

Variation. No prominent variation was found in the morphology among populations.

Distribution. Southern part of Okayama Prefecture, western Honshu, Japan (Fig. 1).

Remarks. Epigynum of Cybaeus momotaro resembles that of $C$. tajimaensis. However, edge of epigynal plate (opening) of this species is more round than that of $C$. tajimaensis. Internal structure of female genitalia of these species are distinct each other.
Cybaeus tajimaensis $\mathrm{n} . \mathrm{sp}$. [Japanese name: Tajima-namihagumo]

(Figs. 7E, 8E, 11C, 18A-C, 19A-B)

Description. Male (holotype). Measurements (in mm). Body length 4.90; carapace length 2.64, width 1.89, head region width 1.05; abdomen length 2.26, width 1.92; sternum length 1.34 , width 1.20 ; labium length 0.27 , width 0.39 . Length of legs (femur/ patella/ tibia/ metatarsus/ tarsus; total): Leg I: $2.12 / 0.76 / 1.96 / 1.93 / 1.32 ; 8.09$. Leg II: $1.95 /$ $0.80 / 1.72 / 1.88 / 1.19 ; 7.54$. Leg III: $1.92 / 0.78 / 1.42 / 1.79 /$

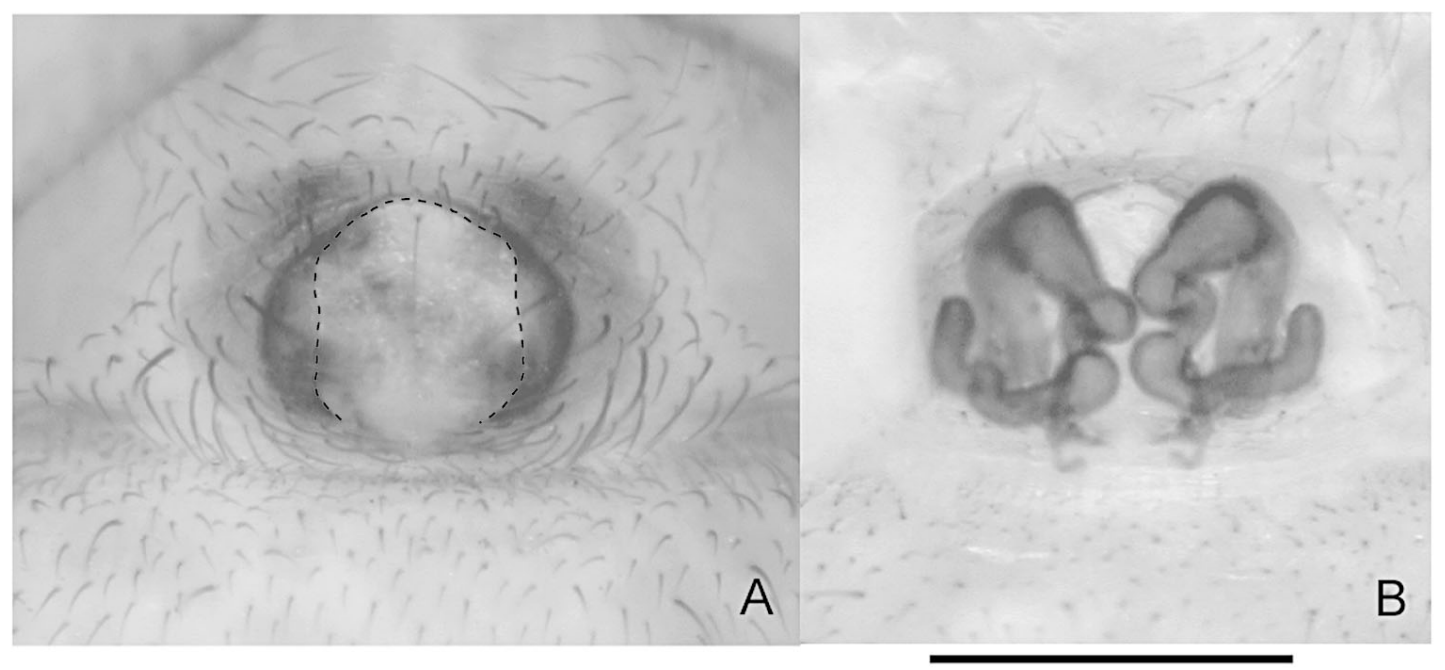

Fig. 14. Female genitalia of Cybaeus mimasaka (paratype)- A epigynum, ventral view; B internal structure, dorsal view. (Dashed line: edge of epigynal plate, Scale: $0.5 \mathrm{~mm}$ ) 


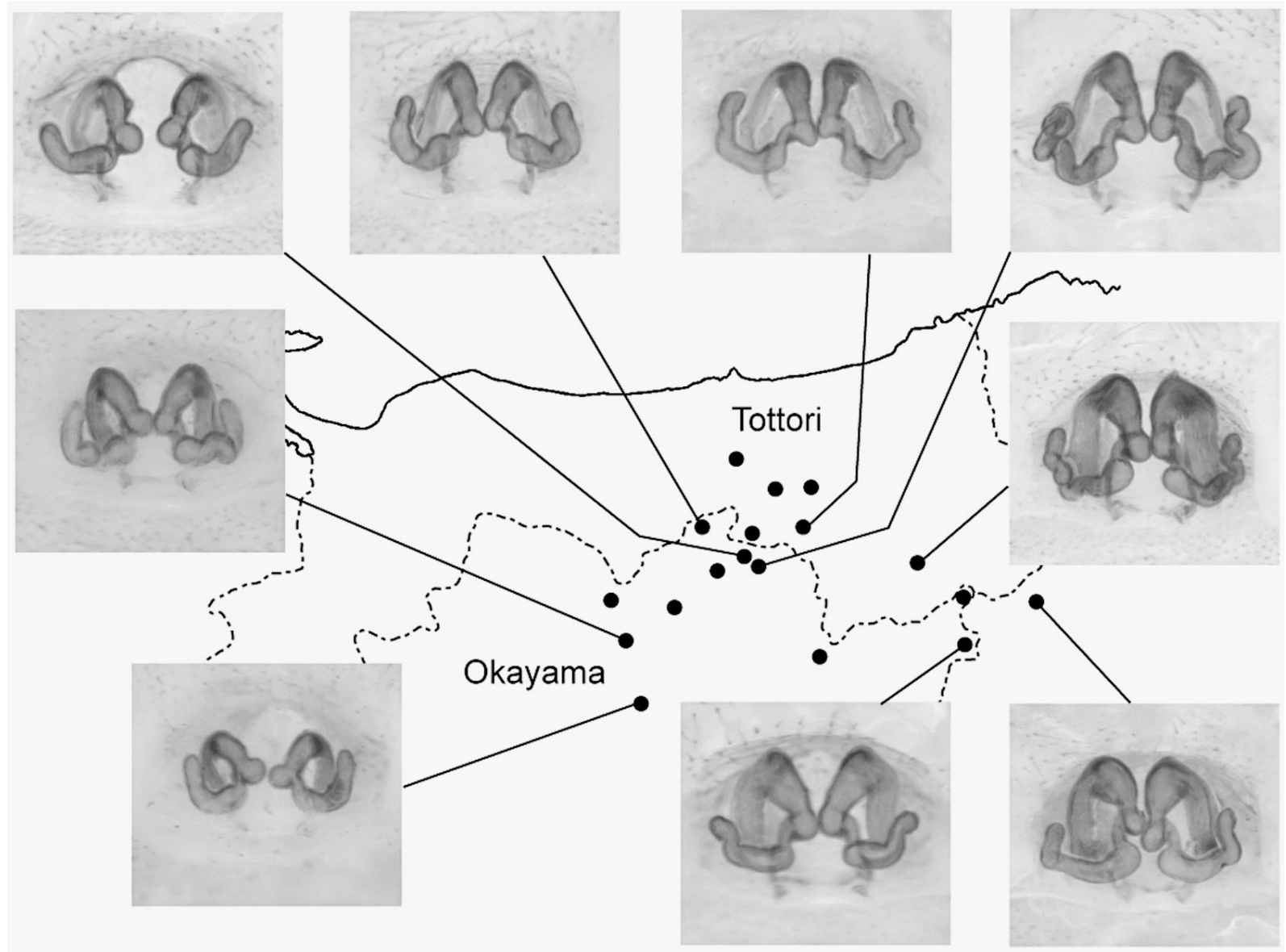

Fig. 15. Geographic variation of female genitalia of Cybaeus mimasaka.

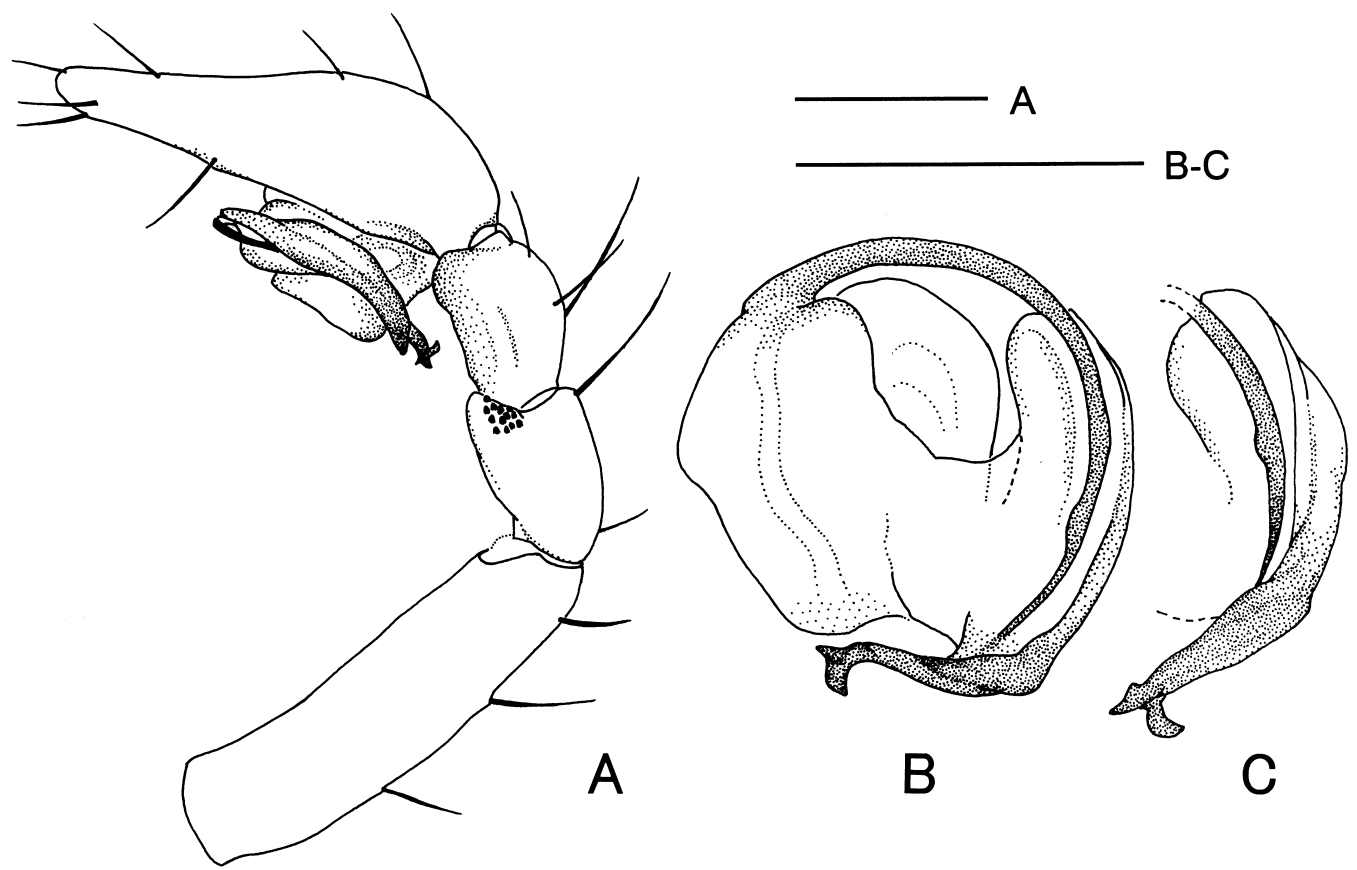

Fig. 16. Male left palp of Cybaeus momotaro (holotype) - A lateral view; B genital bulb, ventral view; C apical element of embolus, ventrolateral view. (Scale: $0.5 \mathrm{~mm}$ ) 


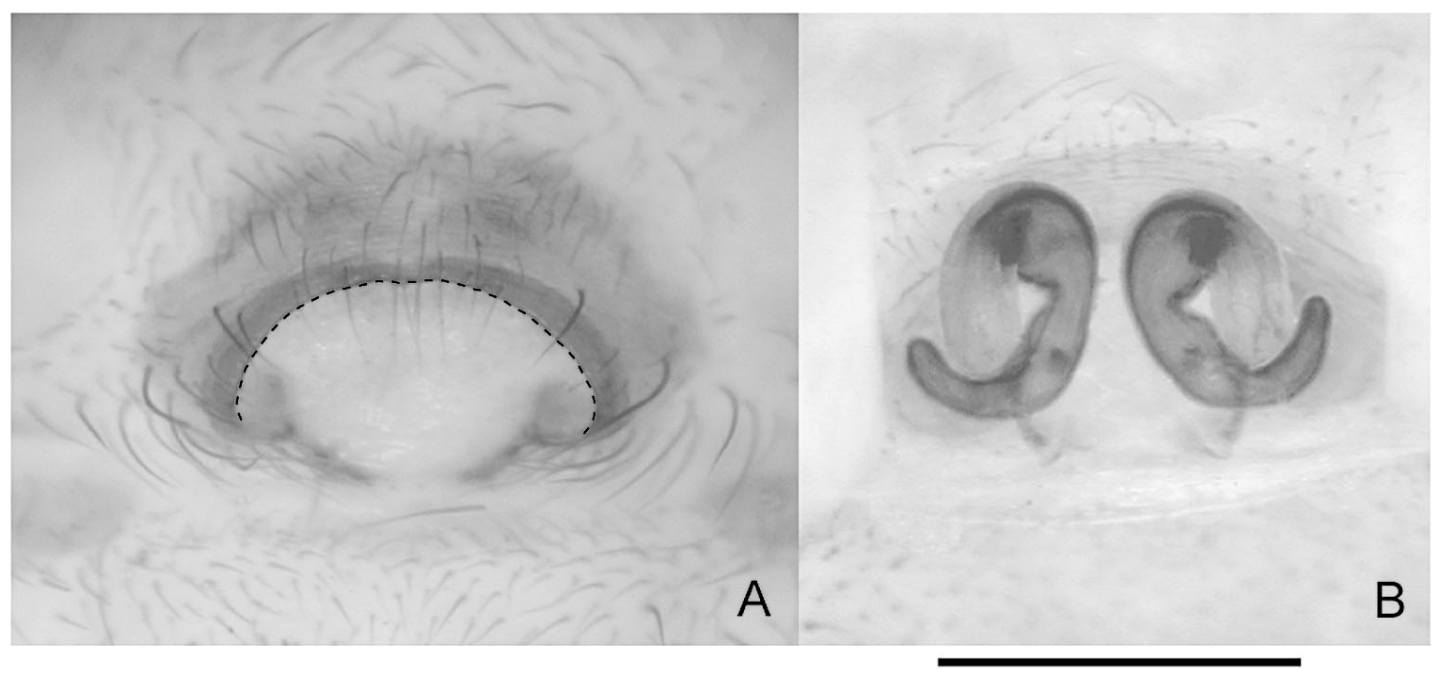

Fig. 17. Female genitalia of Cybaeus momotaro (paratype) - A epigynum, ventral view; B internal structure, dorsal view. (Dashed line: edge of epigynal plate, Scale: $0.5 \mathrm{~mm}$ )

$1.00 ; 6.91$. Leg IV: $2.34 / 0.77 / 2.00 / 2.48 / 1.26 ; 8.85$. Ocular area: length 0.35 , width 0.68 .

Palp (Figs. 7E, 8E, 18A-C). Patellal apophysis relatively long, with 9 conical teeth. Conductor with hook-like apical element of embolus

Female (one of paratypes). Measurements (in $\mathrm{mm}$ ). Body length; 5.40; carapace length 2.74, width 1.85 , head region width 1.16; abdomen length 2.76 , width 2.12 ; sternum length 1.29 , width 1.18 ; labium length 0.32 , width 0.46 . Length of legs (femur/ patella/ tibia/ metatarsus/ tarsus; total): Leg I: $2.03 / 0.81 / 1.79 / 1.66 / 1.04 ; 7.33$. Leg II: 2.01/ 0.82/ 1.61/ 1.62/ 0.98; 7.04. Leg III: $1.77 / 0.73 / 1.28 /$ 1.61/ 0.90; 6.29. Leg IV: $2.18 / 0.76 / 1.83 / 2.22 / 1.06 ; 8.05$. Ocular area: length 0.36 , width 0.78 .

Genitalia (Fig. 19A-B). Opening of epigynum large and wider than long.

Type series. Okuyama, Mori, Yabu-shi, Hyogo Pref., Japan: holotype (ठ); paratypes (1 33 우), 16-X-1992, K. Nojima leg.

Other specimens examined. HYOGO PREF. Yabu-shi: Nagano, 1 132우, 16-X-1992, KN. Kanzaki-gun, Ôkawachi-chô, Kamioda, $4{ }^{\top} 3$ 우, 26-IX-1992, KN.

Variation. No prominent variation was found in the morphology among populations probably due to its narrow range of distribution known by present.

Distribution. Northern part of Hyogo Prefecture, western Honshu, Japan (Fig. 1).

Remarks. Epigynum of Cybaeus tajimaensis also resembles that of $C$. ashikitaensis. However, opening of this species is larger and more concave than that of $C$. ashikitaensis.

\section{Closely related species of the kuramotoi-group}

Cybaeus ashikitaensis has affinities with species of the kuramotoi-group in body size and habitat. This species is similar to the species of kuramotoi-group in fundamental structures of male palp and female genitalia. Furthermore, their distributions show parapatric pattern. However, $C$. ashikitaensis dose not have copulatory plug. Therefore, we hesitate to place this species in the kuramotoi-group at this stage.

\section{Cybaeus ashikitaensis (Komatsu 1968) \\ [Japanese name: Ashikita-namihagumo] \\ (Figs. 7F, 8F, 11D, 20A-B, 21A-B)}

Dolichocybaeus ashikitaensis Komatsu 1968, p. 20, figs.14, 30, 46, 62, 73, 78, 95. (Female holotype from Ashikita Cave, Kumamoto Prefecture, Japan, collected by Teruo Irie, 28VIII-1965, not examined.)

Cybaeus ashikitaensis: Yaginuma 1986, p. 145, fig. 77 (9); Irie \& Ono 2000, p. 177, fig. 11; Ihara 2003, p. 55, figs. 3, 7, 11, 14.

Similar to kuraimotoi-group in external morphology.

Palp (Figs. 7F, 8F, 11D, 20A-B). Cymbium relatively slender. Tibia slightly shorter than patella. Patellal apophysis rounded in apex, with 9 conical teeth. Genital bulb relatively small and conductor simple.

Female genitalia (Fig. 21). Opening slightly concave and relatively small (Fig 21A). Internal structure short in length and spread wide (Fig 21B).

Coloration. Carapace yellowish brown, head region darker. Chelicerae, maxillae, labium and sternum yellowish brown; chelicerae darker than the others. Legs bright yellowish brown with faint annulations. Abdomen dark grayish yellow, dorsally with pale yellow chevron pattern.

Specimens examined. OKAYAMA PREF. Tsuyama-shi: Ayabe, 2ð3ㅇ, 7-X-1992, KN; Haida, 1ð1우, 10-XI-1991, KN. Mitsu-gun, Takebe-chô, Ôda, $1 z^{2} 2$ ㅇ, 3-XI-1990, KN. Akaiwagun, Kumayama-chô, Syakurenji, 23ํㅜㅇ, 10-X-1990, KN. Yoshii-chô: Kurosawa, 3 $3{ }^{\circledR} 2$ ㅇ, 3-XI-1990, KN; Koresato, 


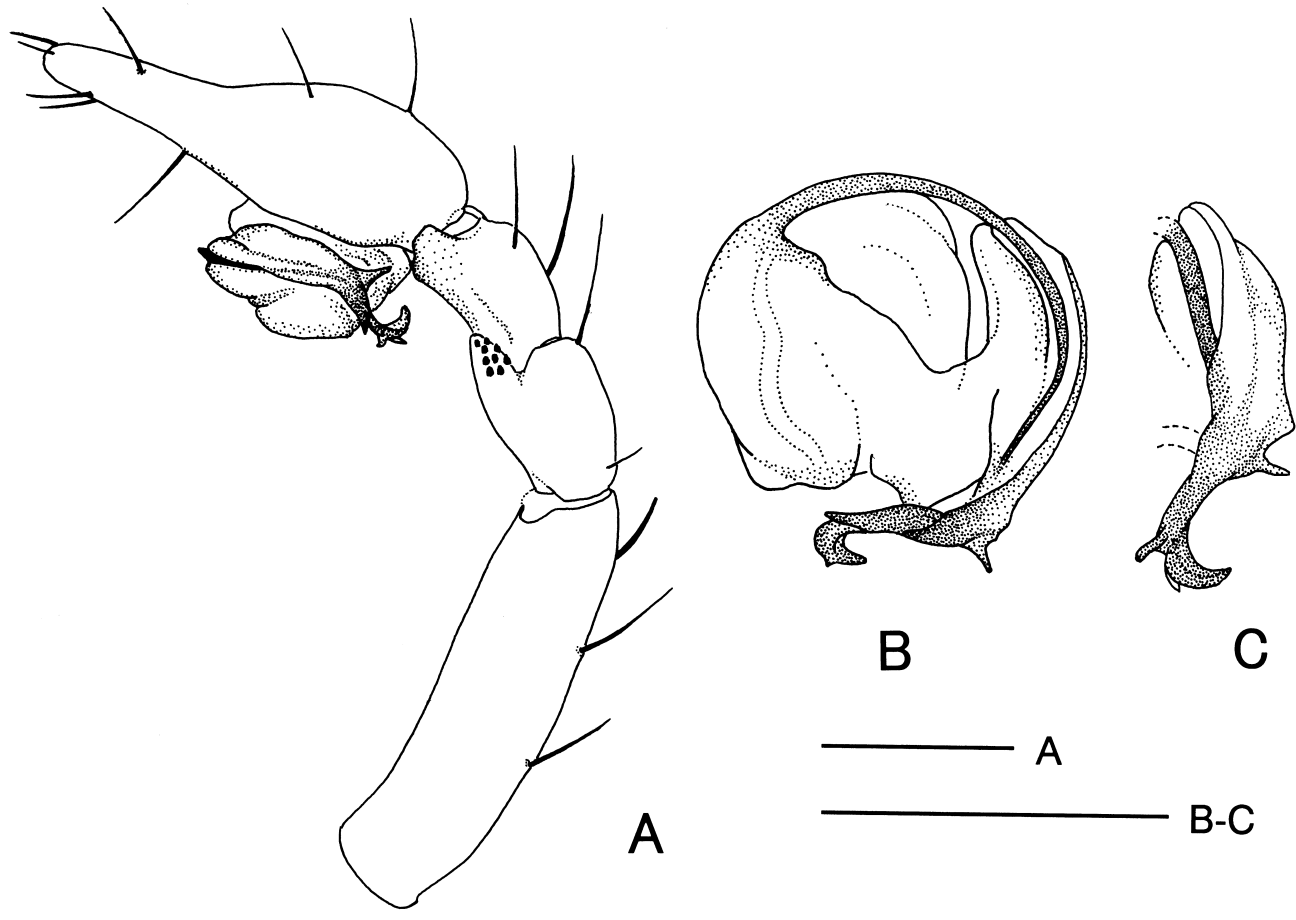

Fig. 18. Male left palp of Cybaeus tajimaensis (holotype) - A lateral view; B genital bulb, ventral view; C apical element of embolus, ventrolateral view. (Scale: $0.5 \mathrm{~mm}$ )

Chiarai-no-taki Falls, 1우, 3-X-1990, KN. Wake-gun, Hinasechô, Sôgo, 6ð3우, 10-XII-1990, KN. Yoshinaga-chô, Tsurugi, 1ð2우, 29-X-1992, KN. Saeki-chô: Iwato, Amenoiwatowake Shrine, 5주우, 10-X-1990, KN; Minamiyamagata, 3주우, 10-X1990, KN; Ôashi Heights, 1우, 6-V-1992, KN. Tomata-gun, Kamo-chô, Aoyagi, 1ð11우, 16-XI-1991, KN. Katsuta-gun, Nagi-chô, Mt. Takiyama: 1우, 19-II-1989, KN; 1ð, 22-X-1989, KN. Aida-gun, Sakutô-chô, Doi: 2ð1우, 1-XI-1989, KN; 1ð, 2-XI-1989, KN. Aida-chô, Aono: 1우, 25-IX-1989, KN; 2우, 26-IX-1989, KN; 1ð, 7-II-1990, KN. Aida-chô, Ôashi Heights,
$3{ }^{7} 6$ 우, 4-XI-1992, KN. Kume-gun, Asahi-chô, Sato, 10, 15-X1990, KN, 1우, 30-X-1990, KN. Kumenan-chô, Tanjôji, 2033우, KN. Kume-chô, Kumekawaminami: 2ð2우, 25-I-1990, KN; 3 우, 12-X-1992, KN. Yanahara-chô: Kose, 3우, 1-X-1989, KN; Sadamune, 1우, 10-III-1991, KN; Mt. Kônomine, 1우, 14-III-1992, KN. HYOGO PREF. Sayô-gun, Sayô-chô, Kuchibase, 2우, 12IX-1989, YI.

Variation. No prominent variation was found in the morphology of male palp and female genitalia among populations within Honshu area.

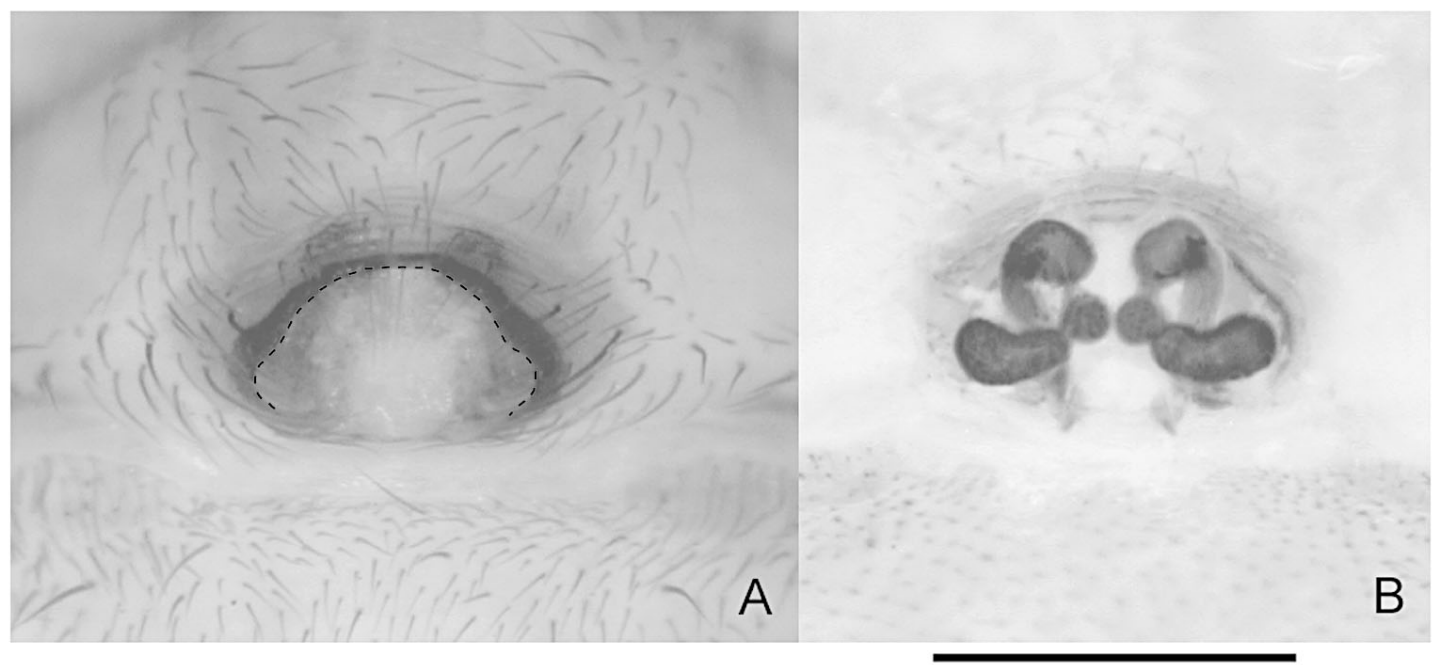

Fig. 19. Female genitalia of Cybaeus tajimaensis (paratype) - A epigynum, ventral view; B internal structure, dorsal view. (Dashed line: edge of epigynal plate, Scale: $0.5 \mathrm{~mm}$ ) 


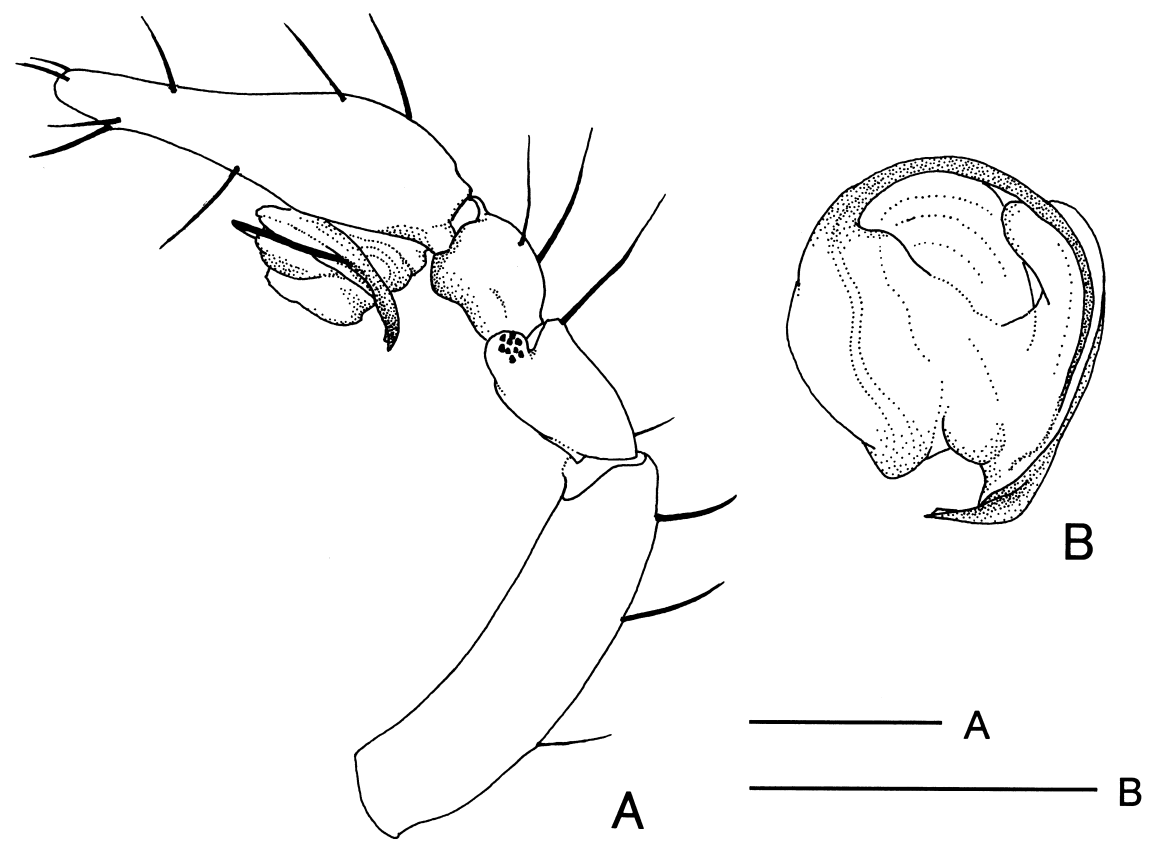

Fig. 20. Male left palp of Cybaeus ashikitaensis (Saeki-chô, Okayama Prefecture) - A lateral view; B genital bulb, ventral view. (Scale: $0.5 \mathrm{~mm}$ )

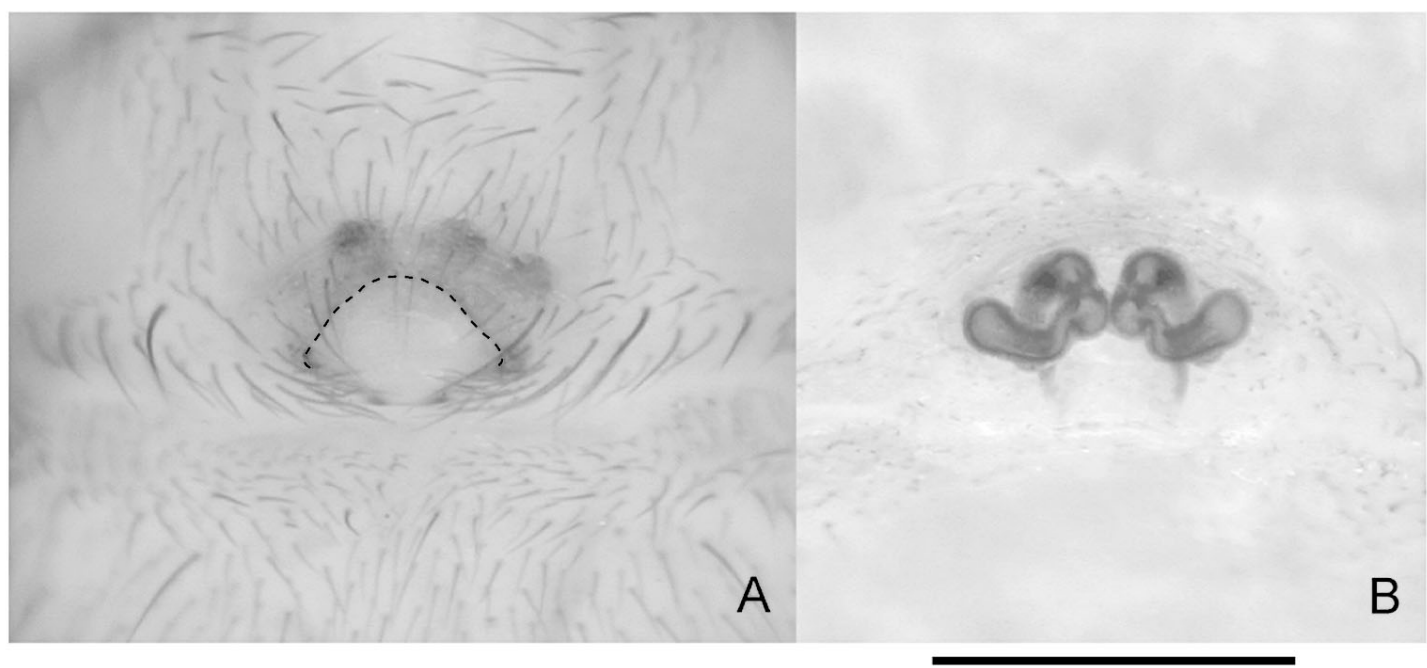

Fig. 21. Female genitalia of Cybaeus ashikitaensis (Saeki-chô, Okayama Prefecture) - A epigynum, ventral view; B internal structure, dorsal view. (Dashed line: edge of epigynal plate, Scale: $0.5 \mathrm{~mm}$ )

Distribution. Southeastern part of Okayama Prefecture and eastern part of Hyogo Prefecture, western Honshu, Japan (Fig. 1).

C. ashikitaensis was originally described from Kumamoto Prefecture and distributed over northern half of Kyushu (Ihara 2003). The distributions of this species are completely separated into two different areas, Honshu (Okayama and Hyogo Prefecture) and Kyushu.

\section{Acknowledgments}

We wish to express our hearty thanks to Dr. Nobuo Tsurusaki, Tottori University, for his long-term direction, reading manuscript of the present paper and offering specimens. We also thank Mr. Kai Ihara, Hiroshima, for helping field collecting.

\section{References}

Ihara, Y. 1993. Five new small-sized species of the genus Cybaeus (Araneae: Cybaeidae) from the Chugoku district, Honshu, Japan. Acta Arachnol., 42: 115-127.

Ihara, Y. 1994. Two new species of the genus Cybaeus (Araneae: Cybaeidae) from the Chugoku district, Honshu, Japan. Acta Arachnol., 43: 87-93.

Ihara, Y. 2003. Cybaeus akiensis n. sp. (Araneae: Cybaeidae) from western Honshu, Japan with some notes on its biology. Acta 
Arachnol., 52: 51-57.

Irie, T. \& Ono, H., 2000. A new species of the Genus Cybaeus (Araneae: Cybaeidae) found in limestone and tuff caves of central Kyushu, Japan. Bull. Natn. Sci. Mus., Tokyo, Ser. A, 26: 173-177.

Irie, T. \& Ono, H. 2003. Notes on spiders of the families Leptonetidae and Cybaeidae (Araneae) from Kumamoto Prefecture, Kyushu, Japan. Bull. Natn. Sci. Mus., Tokyo, Ser. A, 29: 177-183.

Komatsu, T. 1961. Cave spiders of Japan. Their taxonomy, chorology and ecology. Arachnological Society of East Asia, Osaka, $91 \mathrm{pp}$.

Komatsu, T. 1968. Cave spiders of Japan. II. Cybaeus,
Dolichocybaeus and Heterocybaeus (Cybaeinae). Arachnological Society of East Asia, Osaka, 38 pp.

Komatsu, T. \& Yaginuma, T. 1968. A new method for the observation of the spider genitalia. Acta Arachnol., 21: 34

Yaginuma, T. 1963. Spider from limestone caves of Akiyoshi Plateau. Bull. Akiyoshi-dai Sci. Mus., 2: 49-62. (In Japanese with English descriptions)

Yaginuma, T. 1986. Spiders of Japan in color (new ed.). Hoikusha, Osaka. xxiv +305 pp., 64 pls. (In Japanese)

Received November 12, 2004 /Accepted December 10, 2004 